JEL Classification: G24, C14, C22, C52, C53

Keywords: ranking, Value at Risk, Expected shortfall, extreme value theory

\title{
Ranking of VaR and ES Models: Performance in Developed and Emerging Markets
}

\author{
Saša ŽIKOVIĆ—University of Rijeka, Faculty of Economics (szikovic@efri.hr), \\ corresponding author \\ Randall K. FILER—City University of New York, CUNY Hunter College, \\ Department of Economics; CERGE-EI Prague (rfiler@hunter.cuny.edu)
}

\begin{abstract}
There is an inherent problem with comparing and ranking competing Value at Risk (VaR) and Expected shortfall (ES) models since we are measuring only a single realization of the underlying data generation process. The question is whether there is any significant statistical difference in the performance of different models. It all comes down to whether something that we subjectively perceive as different is actually statistically different. We introduce a new methodology for ranking the performance of VaR and ES models based on a nonparametric test. The relative performance of models is analysed using returns for sixteen stock market indices (eight each from developed and emerging markets) prior to and during the global financial crisis. Results show that for a large number of models there is no statistically significant difference. The top performers are conditional extreme value GARCH model and models based on volatility updating. ES results are similar to $V a R$ results with the models being even more closely matched. The same models that were the top performers in VaR comparison also perform significantly better in ES estimation.
\end{abstract}

\section{Introduction}

The years leading up to the recent financial market turbulence have been characterized by exceptionally high growth of the world economy accompanied by moderate inflation. This strong performance resulted in unusually high returns in financial markets, especially in emerging and Anglo-Saxon countries. Risk premia and volatilities were exceptionally low across a very wide spectrum of assets including bonds, stocks, foreign exchange, and derivatives in general. Perception of a low risk environment and strong growth prospects were further fuelled by historically low interest rates, booming real-estate prices and expanding monetary aggregates. The high level of asset prices kept leverage ratios low, while the combination of strong income flows and historically low interest rates did the same with debt service ratios.

However Greenspan (2005) noted: "[...] history has not dealt kindly with the aftermath of protracted periods of low risk premiums". Indeed, historically risk premia and Value at Risk (VaR) measures tend to be at their lowest immediately prior to the outbreak of a crisis or a period of exceptionally high market volatility. In 2007 Knight (2008) warned: "We might be witnessing the proliferation of [...] 'option-like' payoff patterns in the financial system", whereby investors assumed positions that yielded modest but steady income streams in times of prosperity but which could result in large, discontinuous losses in times of crisis. This "pattern" can be attributed to the introduction of new instruments and patterns of behavior that raised the risk of extreme events while giving a false impression of a low- 
risk environment. In hindsight, it is clear that these warnings should have been heeded. The non-linear payoffs during worsening market conditions, combined with the assumptions of normality and IID behavior widely used in VaR models, wrecked havoc on financial institutions, led to a massive need for government intervention in financial markets and created wide-spread doubts about VaR models not only in the eyes of academic community but also among regulators. ${ }^{1}$ Institutional users are the only ones still defending the use of $\mathrm{VaR}$ as the only acceptable risk measure, mostly due to their very relaxed treatment of the true level of risk in banking portfolios. ${ }^{2}$ In general there is a tendency both by financial institutions and by supervisors to overstate the reliability of models and underplay their dangers (see Danielsson, Macrae (2011)).

Since its introduction $\mathrm{VaR}$ as a risk measure has been criticized theoretically, especially for the fact that these models do not account for the extent of losses that could be suffered beyond the specified threshold. In the eyes of investors and regulators, these extreme losses are precisely what a risk measure should flag. VaR is, however, inherently incapable of distinguishing between situations where losses in the tail are only slightly worse than the threshold and those where they are overwhelming. It provides only a lower bound for losses in the tail and thus has a bias toward optimism instead of the conservatism that is generally thought to be beneficial in risk management.

An alternative measure of risk that quantifies losses that might be encountered in the tail is the Expected Shortfall (ES). While VaR represents the minimum loss one expects at a determined confidence level, ES is the expected value of that loss, provided that the loss is equal to or greater than the VaR.

Artzner, et al. (1997, 1999) have shown, using an axiomatic approach to define a satisfactory or "coherent" risk measure, that VaR fails a coherency test because it does not universally exhibit sub-additivity, whereby the risk of a combined portfolio cannot be greater than the sum of the risks associated with any possible division of that portfolio. VaR can only be made sub-additive if the implausible assumption that returns are elliptically distributed is imposed. In this case, however, VaR and ES are equivalent and give exactly the same information (see Embrechts, et al., 1999).

Even though VaR measures have substantial theoretical flaws, they have been imposed on financial institutions as a regulatory obligation under Basel I, II and III rules. There are a number of papers testing the performance of various VaR models in developed and developing markets. Gencay, Selcuk, and Ulugulyagci (2003) and Gencay and Selcuk (2004) analyzed the performance of unconditional Extreme Value Theory (EVT) models against variance-covariance and historical simulation models in nine emerging countries. They found that an unconditional EVT model outperformed classical VaR models at extreme confidence levels. Maghyereh and Al-Zoubi (2006) investigated the relative performance of popular VaR models against an unconditional EVT methodology for seven Middle Eastern and North African countries. Again EVT models outperformed classical variance-covariance and historical simulation models in most cases. Similar results were reported by Mendes

\footnotetext{
${ }^{1}$ see CEBS (Committee of European Banking Supervisors) guidelines, section 4.2. Market risk, December 2009

${ }^{2}$ for example see ESBG (European Savings Banks Group) position paper 0338, March 2010
} 
(2000) for Latin American countries. Cotter $(2004,2007)$ tested a parametric EVT and Gaussian estimates of VaR and ES in six Asian markets during the Asian crisis and five equity indexes from European markets. He found that EVT estimates are superior under both VaR and ES risk measures looking at both the Kupiec (1995) and Christoffersen (1998) criterions, although it was hard to reach any conclusion regarding the significance of these differences. Nyströmand and Skoglund (2002) tested the performance of VaR models on a wide range of assets in developed countries and found that for quantiles higher than the 98 percentile the use of unconditional EVT models made a substantial predictive contribution and that the generalized Pareto distribution more accurately modelled the empirically observed tails than the normal distribution. In contrast to these findings, however, Silva and Mendes (2003) found that the performance of an unconditional EVT model is not satisfactory in meeting Basel II criteria in Asian stock markets since it is overly conservative and thus very expensive for banks. Assaf (2009) and Andreev, et al. (2010) use the conditional generalized Pareto distribution to sucesfully model risks in the emerging market.

ES, on the other hand, although a coherent measure of risk, has not been approved by regulators to calculate capital requirements. This failure is actually quite surprising given that VaR and ES are inherently connected in the sense that ES figures can be easily calculated from the VaR surface in the tail of the distribution except when using conditional quantile modelling. Perhaps because of this lack of approval, ES has not been as extensively studied as VaR in empirical research. Estimation techniques that have been developed for $\mathrm{VaR}$ measures in the past decades, however, can easily be employed to yield superior ES forecasts. This means that advances in VaR estimation need not be lost with the adoption of coherent risk measures into regulatory framework. The inherent connection between VaR and ES is extremely helpful for financial institutions, since all the building blocks required for VaR estimation (databases, risk drivers, calculation routines, etc.) are also needed for estimation of ES. Thus, if an institution has the capacity to calculate VaR, it needs only small adjustments to produce estimates of a coherent risk measure, such as ES. Such a measure should be valuable for internal purposes even before it is required by regulators.

As opposed to the purely VaR-oriented literature, the empirical literature that compares VaR and ES has been limited in both emerging and developed markets. Pattarathammas, Mokkhavesa, Nilla-Or (2008) test the Asian markets during the period 1993-2007 and find strong evidence in favor of using GPD with GARCH and EWMA volatility modelling both for VaR and ES estimation. Kourouma, et al. (2012) test the performance of VaR and ES models in the developed markets during the crisis period and find VaR and ES models based on EVT superior to other tested models.

To remedy the problems of the unconditional estimation that is traditional in EVT, McNeil and Frey (2000) developed a conditional EVT approach to both VaR and ES estimation and showed empirically that the traditional parametric VaR models with normal density fail to accurately estimate losses during financial crises. They, along with others (see Acerbi et al. 2001, Yamai and Yoshiba, 2002 and Inui and Kijima, 2005), advocated the use of ES as an alternative risk measure with good theoretical properties. 
However, ES is also no panacea and has its' own flaws, Yamai and Yoshiba $(2002,2005)$ find that both VaR and ES are not reliable during market turmoil and can give misleading results, although Expected Tail Loss (ETL) is a better choice than VaR. On the other hand Danielsson, et al. (2005), by using the notion of "regular variation" to define heavy tailed distribution, argue that, for heavy tailed returns with well defined mean, VaR can also be sub-additive. Kondor and VargaHaszonits (2008) find that whenever there is an asset in a portfolio that dominates over others in both mean and variance in a given sample, the portfolio cannot be optimized under any coherent measure on that sample, including ES.

Apart from these well known "technical" problems there is also a usually overlooked systemic problem with risk model comparison and ranking. When evaluating and backtesting $\mathrm{VaR} / \mathrm{ES}$ figures we are looking at only a single realization of the underlying data generation process. Consequently, our judgement regarding the performance of particular risk models is based on the performance of the model with regards to only a single occurrence. The VaR model comparison literature is vast but it rarely addresses the question of whether there is truly any significant statistical difference in the performance of different models. Is it only a matter of chance that in a particular market and in particular time period a certain model performs better than some other, or does a certain model consistently and statistically significantly outperform another models over the whole distribution of possible states?

In this paper we first develop a new methodology for VaR and ES model comparison which allows us to rank competing VaR/ES models. Next, we provide an empirical investigation and tail risk assessment of a wide array of VaR and ES models in both developed and emerging countries prior to and during the global financial crisis.

The following VaR models are analyzed in the paper: ${ }^{3}$

(a) Normal simple moving average (VCV) method,

(b) RiskMetrics system,

(c) Historical simulation,

(d) Mirrored historical simulation,

(e) Kernel historical approach,

(f) BRW (time weighted) simulation with decay factors of 0.97 and 0.99 ,

(g) GARCH model,

(h) Filtered Historical simulation (FHS) method,

(i) Unconditional EVT approach using Generalized Pareto distribution (GPD), Conditional EVT approach.

The ES models analyzed in the paper are:

(a) VCV with GPD,

(b) RiskMetrics with GPD,

(c) GARCH with GPD,

\footnotetext{
${ }^{3}$ For a good overview of a wide range of VaR and ES models, including the ones tested in this paper, see Dowd (2005).
} 
(d) Bootstrapped historical simulation,

(e) Bootstrapped "mirrored" historical simulation,

(f) Bootstrapped kernel historical approach,

(g) Bootstrapped BRW simulation,

(h) FHS-ES approach,

(i) Conditional EVT approach,

(j) Unconditional EVT approach.

\section{Value at Risk and Expected Shortfall}

$\mathrm{VaR}$ is usually defined as (see, for example, Alexander, 2001): "the maximum potential loss that a portfolio can suffer within a fixed confidence level (cl) during a holding period".

Let $\left(X_{t}, t \in Z\right)$ be a strictly stationary time series representing daily observations of the negative $\log$ return for a financial asset. The dynamics of $X$ are given by:

$$
X_{t}=\mu_{t}+\sigma_{t} Z_{t}
$$

where the innovations $Z$ are IID with zero mean, unit variance and marginal distribution function $F_{\mathrm{z}}(\mathrm{z})$. It is typical to assume that $\mu_{t}$ and $\sigma_{t}$ are measurable with respect to $\psi_{t-1}$ (the information set up to time $t-1$ ) and that $F_{x}(x)$ denotes the marginal distribution of $\left(X_{t}\right)$. For a horizon $h p, F_{X_{t+1}+\ldots+X_{t+h p} \mid \psi_{t}}(x)$ denotes the predictive distribution of the return over the next $h p$ days, given the information set up to and including day $t$. From a tail event perspective, for a given confidence level $\mathrm{cl}(0<\mathrm{cl}<$ $<1)$, the unconditional $\operatorname{VaR}_{c l}(X)$ is a quantile of the marginal distribution denoted by:

$$
\operatorname{VaR}_{c l}(X)=\inf \left\{x \in R: F_{X}(x) \geq c l\right\}
$$

while the conditional $\operatorname{VaR}_{c l}(X)$ is a quantile of the predictive distribution for the return over the next $h p$ days denoted by:

$$
\operatorname{VaR}_{c l, h p}^{t}(X)=\inf \left\{x \in R: F_{X_{t+1}+\ldots+X_{t+h p} \mid \psi_{t}}(x) \geq c l\right\}
$$

This definition can sometimes be misleading because VaR does not actually represent maximum losses since, as we have seen, a portfolio can lose much more than suggested by $\mathrm{VaR}$ depending on the shape of the tail of the distribution. A more insightful definition, based on equation (2), is:

"VaR is the minimum potential loss that a portfolio can suffer in the 100(1-cl)\% worst cases during a holding period."

or

"VaR is the maximum potential loss that a portfolio can suffer in the $100 \mathrm{cl} \%$ best cases during a holding period."

VaR can be thought of as "the best possible outcome among a set of the worst case scenarios" and, therefore, systematically underestimates the potential losses associated with any specific confidence level. Both VaR and ES contain implicit assumptions regarding agents' risk aversion. If a user has a 'well-behaved' risk-aversion 
function, then the weights will rise smoothly, and the more risk-averse the user, the more rapidly the weights will rise. Given that VaR explicitly weights all losses greater than that at the confidence level as zero it actually assumes that agents are risk-loving (i.e., have negative risk-aversion) in the tail region. ES, in contrast, is characterized by all losses in the tail region (i.e., the $100(1-\mathrm{cl}) \%$ largest losses) having an identical weight. This implies that the investor is risk-neutral in the tail region. Both assumptions seem highly unlikely in real life. Following equation (2), the unconditional ES is defined as:

$$
E S_{c l}(X)=E\left[X \mid X>\operatorname{VaR}_{c l}(X)\right]=-c l^{-1} \int_{-\infty}^{V a R} x f(x) d x
$$

while the conditional ES can be expressed as:

$$
E S_{c l, h p}^{t}(X)=E\left[\sum_{j=1}^{h p} X_{t+j} \mid \sum_{j=1}^{h p} X_{t+j}>V a R_{c l, h p}^{t}(X), \psi_{t}\right]
$$

ES is very appealing as a risk measure because it sums all values of $x$, weighted by $f(x)$, from plus infinity to VaR threshold, thus taking into account the magnitude of potential losses beyond VaR threshold. ES has been referred to in the literature under many names including Expected Tail Loss (ETL), Conditional VaR (CVaR), tail VaR, tail conditional expectation, and mean excess loss. ES has been used by insurance practitioners, especially casualty insurers, for a long time as conditional average claim size. For continuous loss distributions, the ES at a given confidence level is the expected loss given that the loss is greater or equal to the VaR at that level. For distributions with possible discontinuities it has a more subtle definition and can differ depending on whether the loss is strictly greater to the VaR $\left(\mathrm{CVaR}^{+}\right)$or is greater than or equal to the $\mathrm{VaR}\left(\mathrm{CVaR}^{-}\right) . \mathrm{CVaR}^{+}$is also known as "mean shortfall", although the seemingly identical term "expected shortfall" has been interpreted by Acerbi, et al. (2001) as a synonym for $\mathrm{CVaR}$ itself. $\mathrm{CVaR}^{-}$in also known as "tail VaR" (Artzner, et al. 1999).

Although, as discussed above, ES $(\mathrm{CVaR})$ is a coherent measure of risk, it has its own problems. Yamai and Yoshiba $(2002,2005)$ find that even ES, although better at forecasting the true level of risk, it is not reliable during periods of market turmoil and can also give overly optimistic results. In periods of high volatility and/or extreme price spikes, classical, widely used VaR models prove to be overly lax and optimistic.

One possible avenue for improving risk models' estimates lies in extreme value theory (EVT), which specifically models the extreme price changes (i.e., the tails of the return distribution). Focusing on extreme returns rather than the entire distribution seems natural since, by definition, risk management is concerned with measuring the economic impact of rare events.

EVT provides a framework for analyzing extreme (rare) events using historical data. By definition, extreme events are rare, meaning that their estimates are often required for levels of a process that are greater that those in the available data. EVT is based on the Extreme Value Theorem, a relative of the widely used Central Limit Theorem. Suppose we have a set of observed returns drawn from an unknown 
distribution. The EVT says that as the sample size increases, in the limit, the distribution of extreme returns converges to:

$$
\begin{array}{r}
G_{\xi, \sigma, \mu}(x)=\left\{\begin{array}{lr}
1-\left(1+\xi \frac{x-\mu}{\sigma}\right)^{-\frac{1}{\xi}} & \text { if } \xi \neq 0 \\
1-e^{-(x-\mu) / \sigma} & \text { if } \xi=0
\end{array}\right. \\
x \in \begin{cases}{[\mu, \infty]} & \text { if } \xi \geq 0 \\
{[\mu, \mu-\sigma / \xi]} & \text { if } \quad \xi<0\end{cases}
\end{array}
$$

where, $\mu$ is the distribution mean, $\sigma$ is the dispersion of the distribution and $\xi$ indicates the heaviness of the tails.

When $\mu=0$ and $\sigma=1$, the representation is known as the standard Generalized Pareto distribution (GPD). The GPD embeds a number of other distributions. For the analysis of financial time series the most relevant is the heavy-tailed Fréchet distribution in which case the tail index, $\xi$ is greater than 0 .

It is important to be aware of the limitations implied by the EVT paradigm. EVT models are developed using asymptotic arguments, which can create difficulties when applied to finite samples. In order to estimate the tails of the loss distribution we use the result from asymptotic theory that for a sufficiently high threshold $u$, there exists a positive function $\beta(u)$ that satisfies $F u(y) \approx G_{\xi, \beta(u)(y)}$. An approximation of $F(x)$, for $X>u$, can be obtained as:

$$
F(x)=[1-F(u)] G_{\xi, \sigma, u}(x-u)+F(u)
$$

An estimate of $F(u)$ can also be obtained non-parametrically by means of the empirical cdf:

$$
\hat{F}(u)=(n-k) / n
$$

where $k$ represents the number of observations exceeding the threshold $u$ and $n$ the total number of observations. By substituting equation (7) into equation (8), the following estimate for $F(x)$ is obtained:

$$
\hat{F}(x)=1-\frac{k}{n}\left(1+\hat{\xi} \frac{x-u}{\hat{\sigma}}\right)^{-\frac{1}{\hat{\xi}}} \text { given that } G_{\xi, \sigma, u}(x)=1-\left(1+\xi \frac{x-u}{\sigma}\right)^{-\frac{1}{\xi}}
$$

where $\hat{\xi}$ and $\hat{\sigma}$ are the maximum likelihood estimates of $\xi$ and $\sigma$. This equation can be inverted to obtain a quantile of the underlying distribution, which is actually the VaR. For $c l \geq F(u) \mathrm{VaR}$ is calculated as:

$$
V a R_{c l}=q_{c l}(F)=u+\frac{\sigma}{\xi}\left(\left(\frac{1-c l}{\bar{F}(u)}\right)^{-\xi}-1\right)=u+\frac{\sigma}{\xi}\left(\left(\frac{1-c l}{k / n}\right)^{-\xi}-1\right)
$$


Assuming that $\xi<1$, ES is calculated as:

$$
E S_{c l}=\frac{1}{1-c l} \int_{c l}^{1} q_{x}(F) d x=\frac{V a R_{c l}}{1-\xi}+\frac{\sigma-\xi u}{1-\xi}
$$

The estimation of return distributions of financial time series using the EVT has been studied by McNeil (1997); Embrechts, Resnick and Samorodnitsky (1999), Danielsson and de Vries (1997); and Danielsson, Hartmann and de Vries (1998), among others. In all these papers, however, the focus has been on estimating an unconditional (stationary) distribution of asset returns. None of the unconditional EVTbased methods for quantile estimation yields estimates that are easily updated to reflect the recent volatility. Given the conditional heteroskedasticity of most financial data, McNeil and Frey (2000) developed a conditional EVT approach combining GARCH volatility forecasting with EVT tail estimation, which in empirical testing provides very good conditional and unconditional risk coverage.

EVT models are also plagued by problems in the estimation of tail index (see, for example, Diebold, Schuermann, and Stroughair (2000)). Although a number of methods have been proposed for estimation of tail indices, none provide robust results when analyzed over changing sample periods or with the inclusion or omission of extreme values (outliers). Parametric ES estimates, even those based on the GPD distribution, are highly sensitive to functional form misspecification. Simpler parametric models cannot adequately adapt to sudden changes in volatility levels. Nonparametric ES models such as calculating the ES from historical data regarding tail losses are, by definition, unresponsive to shifts in market regimes and the occurrence of extreme events.

\section{Methodology for Comparing and Ranking VaR and ES Models}

In the risk literature there are a number of methods that test the hypothesis whether a certain model is better than some other model, such as Diebold and Mariano (1995) equal predictive ability (EPA), White (2000) reality check (RC) and Hansen (2005) superior predictive ability (SPA). The question of interest in all of these tests is whether an alternative forecast is better than the benchmark forecast, or equivalently, whether the best alternative forecasting model is better than the benchmark. This question can be addressed by testing the null hypothesis that the benchmark is not inferior to any alternative forecast. For a more complete discussion on this issue, see Sullivan, Timmermann, and White (2003) and references therein. Such tests are useful for a forecaster who wants to explore whether a better forecasting model than the model currently being used is available. After a search over several alternative models, the relevant question is whether the observed excess performance by an alternative model is significant or not. Tests for equal predictive ability (EPA), in a general setting, were proposed by Diebold and Mariano (1995) and extended by West (1996), to accommodate the situation where forecasts involve estimated parameters. A test for comparing multiple nested models was given by Harvey and Newbold (2000) and Mc-Cracken (2000) derived results for the case with estimated parameters and non-differentiable loss functions, such as the mean absolute deviation loss function. West and McCracken (1998) developed regression-based tests and other extensions were made by Harvey, Leybourne, and Newbold (1998), West (2001), and Clark and McCracken (2001) who considered tests for forecast encompassing. 
Recalling the problem posed by the fact that comparisons are typically based on a limited sample of revelations from the population of return distributions, the proposed ranking procedure for competing VaR/ES models is performed according to Lopez score (1998) for VaR models and modified Blanco-Ihle error statistic (1998) for ES models. The reason for using different measurement metrics stems from the simple fact that metrics intended to measure VaR performance need to measure the frequency and distance of VaR exceedances while ES metrics measure the closeness of fit between realized and forecasted excess losses. The proposed ranking procedure consists of:

1. Fitting an ARMA-GARCH model to the natural logarithm of the time series in order to obtain IID observations.

2. Estimating the empirical CDF of each time series (applying it to the non-tail regions of distribution) with a Gaussian kernel. This smoothes the CDF estimates, eliminating the staircase pattern of unsmoothed sample CDFs.

3. Finding the upper and lower thresholds such that $x \%$ of the residuals are reserved for each tail and fitting the amount by which those extreme residuals in each tail fall beyond the associated threshold to a parametric GPD.

4. Generating $N$ simulated paths for the residuals from the obtained semiparametric distribution (each path is $T$ observations long).

5. Adding the ARMA-GARCH model to the residuals to obtain $N$ x $T$ simulated time series returns.

6. Calculating VaR/ES for each of the $N \times T$ simulated returns for each VaR/ES model.

7. Calculating $N$ Lopez/modified Blanco-Ihle scores for each of the $N \mathrm{VaR} / \mathrm{ES}$ simulated return pairs, for each VaR/ES model.

8. Comparing if the mean values of the Lopez/modified Blanco-Ihle scores for different VaR/ES models are significantly different from each other. For this purpose one-way ANOVA approach is employed. The purpose of one-way ANOVA is to find out whether data from several groups have a common mean. The $p$-value returned by ANOVA depends on assumptions about the random disturbances in the model equation. For the $p$-value to be correct, these disturbances need to be independent, normally distributed, and have constant variance.

9. Checking for autoregression, heteroskedasticity and normality in the Lopez/ /modified Blanco-Ihle scores. If the data is not normally distributed it needs to be transformed to uniform variates by empirical CDF and then to normal via inverse CDF after which one-way ANOVA can be calculated. Critical values used for the multiple comparisons are based on Tukey-Kramer honestly significant difference criterion (see Zar (1984)) since it is optimal for balanced one-way ANOVA. An alternative that we use in this paper is the non-parametric Kruskal-Wallis test (see Linton, Harder (2007)), a nonparametric version of one-way ANOVA, which makes only mild assumptions about the data and is appropriate when the distribution of the data is non-normal. The assumption behind this test is that the measurements come from a continuous, but not necessarily a normal, distribution. The test is based on an analysis of variance using the ranks of the data values, not the data values themselves. 
An obvious limitation of this approach is the assumption that the description of the central mass and the tails of the process distribution are adequate. This is not an unusual or strong assumption and is made in all the models that are used in practice. We do not accept, however, that the single visible realization of the underlying process is the "ultimate truth" but, by simulating the data, allow for stochastic randomness. Even so, when thinking about the nature of forecasting one is always faced with inherent problem of forecasting the future by using only visible past data.

\section{Data and Backtesting Methodology}

We analyze the performance of the various VaR and ES models summarized in Table 1 (see Appendix) using the log of daily returns of eight equity indices from developed markets (US-Dow Jones Industrial (DJIN), Nasdaq, S\&P 500, Russell 2000 (RTY); Japan-Nikkei; Germany_DAX; France-CAC; and UK_FTSE) and eight emerging markets (Brazil-Bovespa; Russia_CRTX; India-Sensex; South Africa-Jalsh; Malaysia-KLCI; Mexico-Mexbol; Hong Kong-Heng Seng; and Taiwan-Taipei). Returns were collected from the Bloomberg website for the period January 1, 2000 through July 1, 2010. In order to differentiate between "normal" and stressed market conditions we choose two backtesting periods consisting of 750 observations each. The period between June/July 2004 and June/July 2007 forms the precrisis backtesting period, and the period between June/July 2007 and July 2010 forms the crisis backtesting period. VaR and ES figures were calculated for a one-day ahead horizon and 99 percent confidence level. Based using the proposed ranking procedure the VaR models are tested using: Kupiec test, Christoffersen Unconditional Coverage (UC), Conditional Coverage (CC) and Independence (IND) test, and Lopez and Blanco-Ihle tests as well as root mean squared error (RMSE) and mean average percentage error (MAPE) statistics. The Christoffersen UC test is problematic because it gives a distorted image of VaR models' performance. Since it is chi-square distributed with one degree of freedom, deviations from the test's expected value that occur on the conservative side (i.e. with number of exceedances lower than their expected value) are penalized more severely. This characteristic is not compatible with risk-averse or risk-neutral assumptions. Thus, from the regulatory standpoint, the Kupiec binomial test is preferable to the Christoffersen UC test because it is more desirable to have positive than negative deviations. The same logic extends to Christoffersen conditional coverage (CC) test, which should also be treated sceptically since it automatically disadvantages $\mathrm{VaR}$ models that err on the conservative side.

Blanco and Ihle (1998) suggested evaluating forecasts according to a loss function equal to $\left(L_{t}\right.$ being the loss at time $\left.t\right)$ :

$$
C_{t}=\left\{\begin{array}{ccc}
\frac{L_{t}-V a R_{t}}{V a R_{t}} & \text { if } & L_{t}>V a R_{t} \\
0 & \text { if } & L_{t} \leq V a R_{t}
\end{array}\right.
$$

This loss function allows for the sizes of tail losses to influence the rankings of VaR models. Models that generate higher tail losses would generate higher values under this size-adjusted loss function than models that generate lower tail losses, ceteris paribus. The problem with the Blanco-Ihle loss function is that it compares 
the calculated VaR with tail losses, which does not make sense since VaR forecasts only the least possible tail losses. Since VaR does not contain any information about the size of the expected tail loss, the Blanco-Ihle loss function only measures the discrepancy between the lowest possible tail loss and actual tail losses. The Blanco-Ihle loss function can easily be modified to compare ES with the actual value of the tail loss, a more meaningful comparison. The modified function equals:

$$
C_{t}=\left\{\begin{array}{ccc}
\frac{\left|L_{t}-E S_{t}\right|}{E S_{t}} & \text { if } & L_{t}>\operatorname{VaR}_{t} \\
0 & \text { if } & L_{t} \leq \operatorname{VaR}_{t}
\end{array}\right.
$$

In order to select superior ES models, each model will be graded by four symmetrical error statistics: the mean absolute error (MAE), two versions of the root mean squared error (RMSE), and the proposed ES modification of the Blanco-Ihle loss function. Among these error statistics, ES modification of the Blanco-Ihle loss function is probably the most informative, since it compares the tail loss to ES while taking into account the relative size of the tail loss compared to the difference between the two. In our two-stage backtesting procedure, the best performing VaR/ES model must first satisfy both the Kupiec and Christoffersen independence (IND) tests and then provide superior tail loss forecasts, in the sense of minimizing the error statistics.

\section{Backtesting Results and Findings}

To secure the same out-of-the-sample backtesting period for all of the examined stock indices, the out-of-the-sample data sets are formed by removing the 1.500 most recent observations from each stock index and forming two sub-periods of 750 days. The first sub-period from June/July 2004 to June/July 2007 represents the precrisis period. The second sub-period from June/July 2007 to July 2010 represents the crisis period. The remaining observations are used to calculate the VaR and ES starting values and calibrate volatility. The length of the tail-loss data set used for backtesting depends on the number of errors generated by each VaR model. The quality of ES forecasts depends on both the ES estimation model and the quality of the VaR forecast. This dependence can be easily seen from the simple fact that a loss that might fall in the extreme range under one VaR model and, as such, be included in the ES forecast might not exceed another, more conservative, VaR measure.

Data from all the analyzed stock indices shows leptokurtosis, asymmetry and significant heteroskedasticity, with autoregression being especially pronounced in the emerging markets. Based on the Akaike and Bayesian information criteria asymmetric EGARCH representation of volatility with GED and Student's $t$ distribution was used to capture the dynamics of data-generating processes. The asymmetry parameter in the EGARCH model was significantly different from zero for most of the indexes. ${ }^{4}$ The asymmetry parameter, which controls the asymmetric impact of positive and negative shocks on conditional variance, indicates significantly higher conditional volatility after negative shocks.

\footnotetext{
${ }^{4}$ For the BOVESPA, CRTX, JALSH, KLCI and HENG SENG indices the asymmetric impact is not significantly different from zero. Results are available from the authors on request.
} 
Estimation of the tail index parameter is crucial in applying EVT models, which are directly linked to threshold value $u$ which defines the level above which returns are considered extreme. The threshold value for each index was determined by comparing the Hill estimator with the mean excess plot and the quantile-quantile (QQ) plot (Danielsson and de Vries, 1997). The same procedure of estimating the threshold value was also performed on IID innovations required for the implementation of the McNeil and Frey (2000) EVT-GARCH model. Maximum likelihood estimates (MLE) of the shape (tail index) and scale (sigma) parameters for the GPD, during the pre-crisis and crisis period, for the analyzed stock indices' threshold losses (losses surpassing the threshold value set by Hill estimator), and threshold innovations are presented in Appendix in Table 2. The mean excess and QQ plots, Hill estimator and MLE show that majority of tail indexes for both developed and emerging countries are greater than zero, although not always statistically significant, implying the possibility of fat tails and that the GPD belongs to the Fréchet and Gumbel domains of attraction. In the pre-crisis period the tail indexes vary between -0.195 (FTSE) and 0.129 (NIKKEI) for the developed markets and between -0.074 (MEXBOL) and 0.173 (HENG SENG) for the emerging markets. During the crisis most of the tail indexes changed substantially and ranged between -0.042 (NASDAQ) and 0.18 (S\&P500) for the developed markets and between -0.099 (MEXBOL) and 0.251 (JALSH) for the emerging markets. The greatest changes in the size of the tail index between the two periods were recorded for FTSE (0.253) and CRTX (0.214). The distribution of tail losses for the stock indices in South Africa, Hong Kong and Russia shows that they may not even have a finite fourth moment, since the estimated tail index is around 0.25 . $^{5}$ The tails of the innovations from the analysed time series are similar to the values of returns. Since we are measuring the tail index of the extreme left (negative) tail of the distribution of returns, the impact of severe crashes in the stock markets is directly reflected in the increased size of the extreme left tail. The visible change in the fatness of the left tail (high tail index) in the majority of markets is a clear warning sign that the dynamics of the markets have shifted towards a more extreme end of the spectrum.

As is visible from Table $3 a$ (in Appendix), during the pre crisis period, in both developed and emerging markets, satisfactory performance with regards to Basel and independence criteria is recorded for nonparametric models (HS, MHS and KHS) as well as FHS and extreme value based approaches. Very weak performance is recoded for BRW, VCV, RiskMetrics and Hull-White models. As we shall see, the performance of the tested VaR models is significantly different during the crisis period. In developing markets good performance is recorded for the Hull-White, GPD and EVT-GARCH models.

For the crisis period, for which the VaR models performance with regards to Basel and independence criteria is presented in Table $3 b$, we make a distinction between the standard EVT GARCH model and EVT GARCH (L) model, where $\mathrm{L}$ stands for a longer time series. We introduce two EVT GARCH models and this notation because we find an interesting pattern of behavior-if we use the standard

\footnotetext{
${ }^{5}$ For $\xi>0, E\left[X^{k}\right]$ is infinite for $k>1 / \xi$. The number of finite moments is ascertained by the value of $\xi$ : if $0.25 \leq \xi \leq 0.5$ the second and higher moments are infinite; if $\xi \leq 0.25$, the fourth and higher moments are infinite.
} 
rolling window for GARCH parameters (calculated just in the crisis period) and from that calculate standardized innovations, EVT GARCH forecasts are very poor. This is due to the very thin tail indicated by fitting the GPD. If, instead, we use a longer period such as 6 years, results are much better since the GPD tail is closer to what we might expect. At first sight this finding indicates counter-intuitive behaviour (if we are using newer information we should have better volatility forecasts ergo better risk measures). In reality, if we are using a very accurate volatility forecast reflecting the current environment there is a lack of outliers and standardized innovations are bunched around zero with their tails exponentially decreasing. When calculating GPD parameters from such a innovation series it is logical to obtain low, or even negative, estimates of the tail parameter. The paradox lies in the fact that if the volatility estimate is fairly good but not perfect there will be outliers in the standardized innovations series which will lead to higher a GPD tail index and thus actually increase the accuracy of EVT GARCH VaR forecasts. In emerging markets only the EVT GARCH (L) and MHS 250 models performed satisfactorily, again with a clear distinction between standard and prolonged EVT GARCH models.

Overall we find good performance across both developed and emerging markets for extreme value based approaches. Mirrored historical simulation, a simple extension of historical simulation, yielded surprisingly good risk coverage and satisfied the backtesting criteria for a great majority of stock indices tested. Backtest results also show that the kernel historical approach VaR estimator, although inferior to mirrored historical simulation, delivers significant variance and mean square error reductions when compared to plain historical simulation. This difference is similar to that found by Chen and Tang (2005).

It is also useful to analyze the averages of $\mathrm{VaR}$ forecasts for the models that satisfy the Basel II/III-required Kupiec test as well as the Christoffersen independence criterion. Rankings according to the minimum average VaR value (provided the Basel II/III criteria and Christoffersen independence test at a 5 percent significance level are satisfied) are presented in Table 4 (in Appendix). For all of the indices in both developed and emerging markets, GPD and HW models provide the highest VaR estimates, with HW providing very high values during the crisis period. This characteristic makes them the most conservative but also the most expensive in terms of capital requirements for financial institutions. During the precrisis period for the developed markets, the GARCH model yielded the lowest average VaR four out of eight times (Nikkei, DAX, CAC and FTSE index) followed by BRW simulation with a decay factor of 0.99 , which was the best performer in two cases (DJIN and Nasdaq index). For emerging markets, the performance of GARCH model is even better, yielding the lowest average VaR for five out of eight indices (BOVE, Mexbol, KLCI, SENSEX and Heng Seng index). During the crisis period for the developed countries EVT GARCH (L) was the top performer (S\&P 500, DJI, NASDAQ and FTSE index), followed by FHS model (RTY, Nikkei, DAX). For emerging markets, both GARCH and FHS models were the best performers for three indexes. In summary, among VaR models that satisfy the Basel criteria, the FHS and GARCH models provided the lowest average $\mathrm{VaR}$ in most cases, making them the models with the lowest opportunity cost of holding idle capital. Results of the Lopez size adjusted test, presented in Tables $5 a$ and $5 b$ (in Appendix), are very similar to the minimal average VaR values, especially in the crisis period with the EVT-GARCH model 
having the best Lopez score in the developed markets and FHS model having the best score in the emerging markets. Strong performance of EVT based models both in developed and emerging markets is in general consistent with the findings of Gencay, Selcuk, Ulugulyagci (2003), Gencay, Selcuk (2004), Maghyereh, Al-Zoubi (2006) and Cotter (2007).

According to the conventional investment logic one might expect that the performance of VaR models is better adapted to developed and liquid markets than emerging ones. Our backtesting results during the crisis period, however, show quite the opposite. Nonparametric models (especially mirrored HS models), as well as parametric GARCH and FHS models, perform far better in emerging markets than developed ones. These results confirm that regulators and investors should change their traditional perception that since emerging markets are more volatile and less developed they need more robust risk measures, while VaR models are adequate for "tranquil" and "well behaved" developed markets. One explanation for such nonconformist VaR performance is based on the simple fact that since the emerging markets are usually more volatile and experience more frequent market crashes, parameters of VaR models are more attuned to such events. Thus, if the observation windows used for nonparametric $\mathrm{VaR}$ models are long enough, they will contain a significant number of past crashes and parameters of the classical parametric and EVT VaR models will be more in line with the volatile and crash prone environment. On the other hand, developed markets, having experienced positive and steady growth for almost a decade, mislead the VaR models by lacking high volatility and crashes in the information set. In such circumstances, regulators and investors should be even more worried about the reality and usefulness of traditional VaR risk measures when applied to portfolios containing mostly stocks from developed markets as opposed to emerging ones.

To backtest the various ES models, we ranked the models by their ability to yield minimal loss functions, i.e. the minimum departure from the reported tail loss values. Rankings of the ES models according to modified Blanco-Ihle error statistics at the 99 percent confidence level are presented in Table 6 (in Appendix). According to the modified Blanco-Ihle statistic, in the pre-crisis period, both in the developed and emerging markets, the bootstrapped MHS model was the best performing ES model. In the developed markets the basic bootstrap historical simulation model followed closely. In emerging markets, bootstrapped FHS and GPD model were ranked as second and third performers. The worst performers across all the markets were the VCV, RiskMetrics and GARCH models with GPD distribution. During the crisis period, both in the developed and emerging markets bootstrapped FHS, MHS and EVT GARCH were the best performing ES models. The worst performing models were again the VCV, RiskMetrics and GARCH models with GPD distribution.

In summary, backtesting results show that bootstrapped mirrored historical simulation is the superior ES measure. We find no benefit to using a kernel approach instead of bootstrapped historical simulation. This finding is similar to that reported in Chen (2008) for plain historical simulation. The underlying reason that there is no benefit from kernel smoothing of ES estimates lies in the fact that the unconditional ES is a mean parameter, which can be estimated accurately by simple averaging and therefore does not call for additional data smoothing. It is also interesting to note 
that, although historical simulation models are clearly inferior to EVT models in VaR estimation, in ES estimation bootstrapping historical exceedances over VaR performs better than theoretically well-founded EVT models.

Going beyond standard VaR/ES performance reporting, we apply the methodology presented in section 3 to test whether there is any statistically significant difference in the performance of the various VaR and ES models. The data is simulated based on the distribution of returns in the crisis period. For each index, 2,000 simulations were performed with length of each simulated index being 1.000 data points. Since we are using Lopez size adjusted score (modified BlancoIhle) metrics for VaR (ES) model comparison, the closer the score of an individual model is to zero, the better the performance. After obtaining 2,000 Lopez size adjusted (modified Blanco-Ihle) scores for each VaR (ES) model and for each of sixteen index data generating processes we apply a non-parametric Kruskal-Wallis test to determine the existence of statistically significant differences between competing VaR(ES) models. Results are reported in Table 7 (in Appendix). If the simulated mean value of the $\operatorname{VaR}(\mathrm{ES})$ model lies outside of the $95 \%$ confidence interval of all the other tested models that model is ranked according to its relative performance. If a model is not significantly different from all the other models it shares the same ranking as the models not significantly different from it. Analysing the VaR model performance on simulated data, presented in Table 7a, for a large number of different models there is no statistical difference in their performance. When looking at overall performance in the developed markets the best performing VaR model that is statistically different from other tested models is the conditional EVT GARCH model, followed by the unconditional GPD model. Even in the summary results across eight developed markets there is no statistical difference between the FHS and BRW $(\lambda=0.99)$ models. Considering that recently Žiković, Aktan (2011) showed a way how to improve the performance of BRW model the results are even more indicative. In the emerging markets overall the best model is MHS 250, followed by EVT GARCH model. Similarly to the developed markets there is again an overlapping between the FHS and MHS 500 models. The statistically worst performing VaR models across both markets are the simplest models, the Normal VCV, plain historical simulation and RiskMetrics models. Overall, the statistically significant top performers are conditional EVT GARCH, models based on volatility updating (HW and FHS) and nonparametric mirrored historical simulation. Since our metric of choice is the size adjusted Lopez score, these models provide the closest fit to the actual level of risk encountered in the analysed markets. The results are consistent with Assaf (2009) and Andreev et al. (2009) which also find that VaR estimates based on EVT perform significantly better than conventional models and that risk assessment should not neglect the tail behavior since it may lead to an improper evaluation of market risk.

ES backtesting results are similar to VaR results with the models being even more closely matched. A noticeable difference from the VaR results is that the mirrored historical simulation model is similar in rank or even superior to the conditional EVT GARCH model. In the developed markets the best ES models were MHS 250 and FHS followed by conditional and unconditional extreme value based models. In the emerging markets EVT GARCH is the best performing model followed by both MHS models and FHS. Again the same models that were the top 
performers in the VaR comparison perform significantly better then other tested models. We find no benefit to using a kernel approach instead of bootstrapped historical simulation. It is interesting to note that, although historical simulation models are clearly inferior to EVT models in VaR estimation, in ES estimation bootstrapping historical exceedances over $\mathrm{VaR}$ often perform better than theoretically better-founded EVT models which is in contrast to Pattarathammas, Mokkhavesa, Nilla-Or (2008) and Kourouma, et al. (2012) who strongly prefer the EVT based approach with EWMA and GARCH volatility.

\section{Conclusion}

Our findings show that the mainstream opinion that VaR models are better adapted to developed and liquid markets as opposed to the emerging ones is ill founded, especially during a crisis period. Regulators, as well as investors, should change their misperception that since, emerging markets are more volatile and less developed, only they need more robust risk measures and using VaR models is adequate for "tranquil" and "well behaved" developed markets. A protracted period of prosperity and tranquillity is precisely why VaR models underperform especially severely during the crisis in the developed markets. Such circumstances mislead VaR models in the developed markets since, unlike the emerging markets, they may lack severe volatility and crashes in the information set for extended periods, with the resulting estimated parameters lying further outside the area of previous support when a crash does come. In such circumstances regulators should be even more wary about the usefulness of traditional VaR risk measures when applied to portfolios containing mostly stocks from developed markets. As our results warn, greater attention must be given to realistically modelling the tails of the distribution and choosing the most realistic approach to VaR and ES modeling even if it means lower investment profits. Although the industry is opposing such moves, due to inevitable rise in required capital reserves and lower short-term profitability, in order to construct a sound risk management framework regulators must take into account the fragility of VaR models which also extends to a degree to ES models. As we show there is far less difference between competing VaR/ES models than thought and only a few models are significantly superior. Our results cast doubt on VaR/ES model comparison studies since they mostly measure the performance of the analysed risk models on a single realization of the data generating process. As we have shown such evaluation of model performance can often be misleading. 


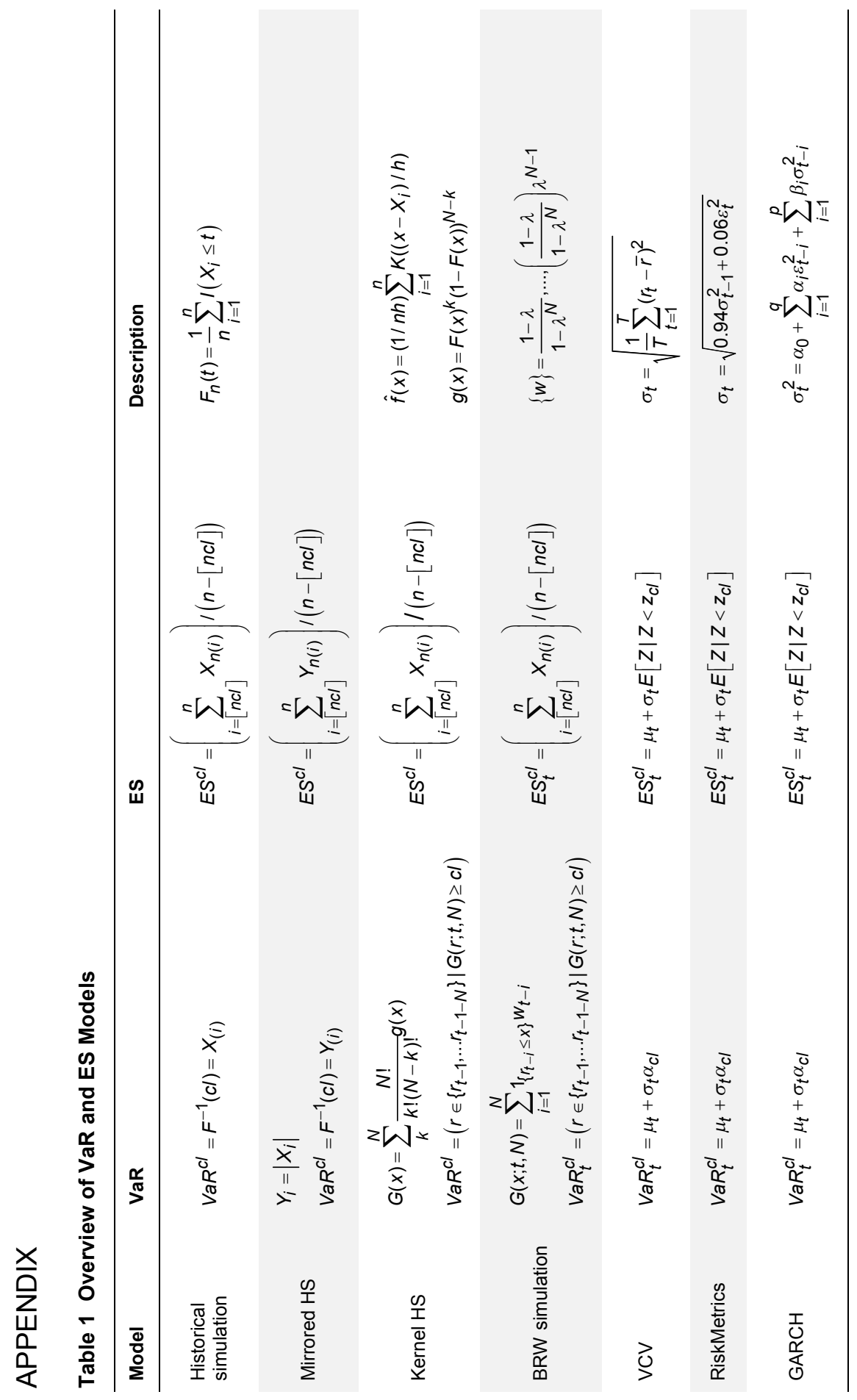

Finance a úvěr-Czech Journal of Economics and Finance, 63, 2013, no. 4 


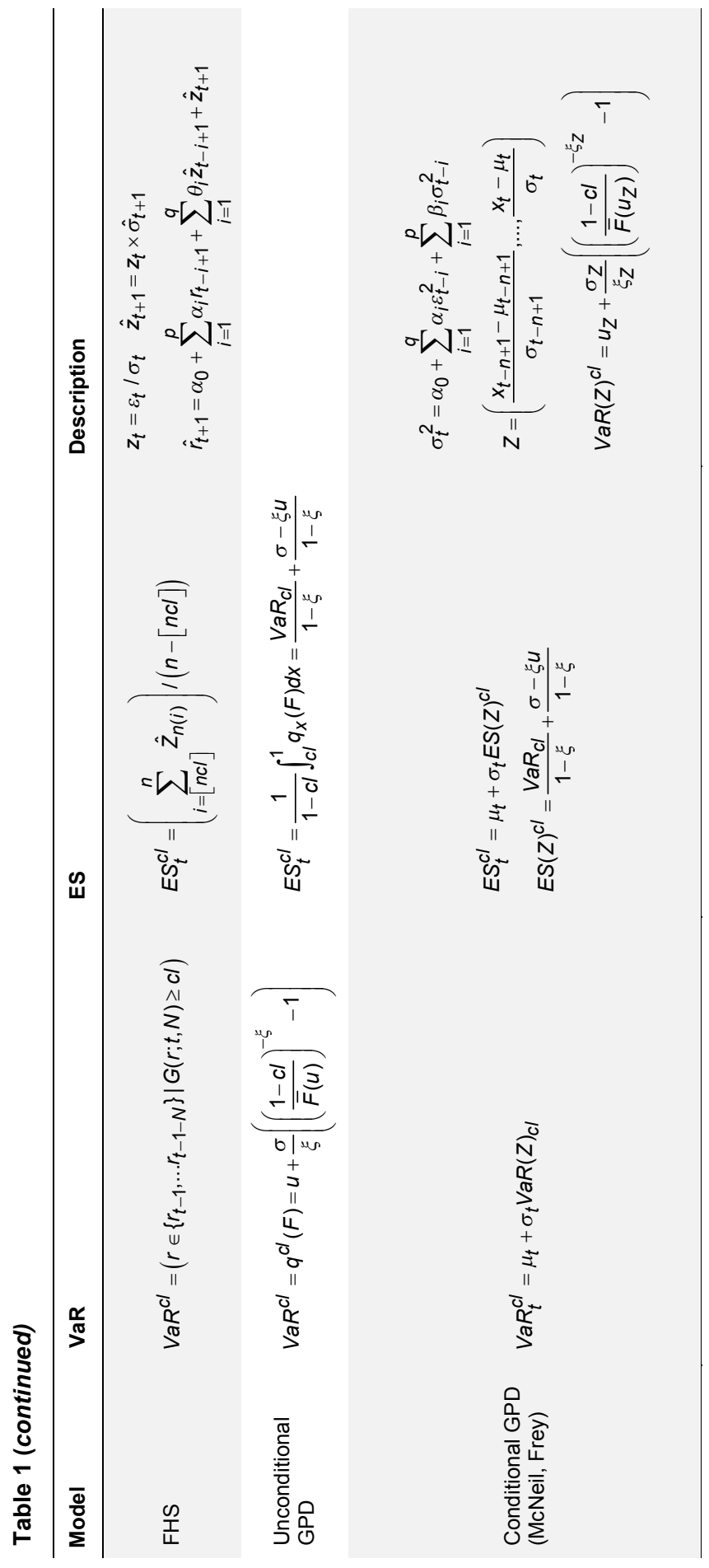




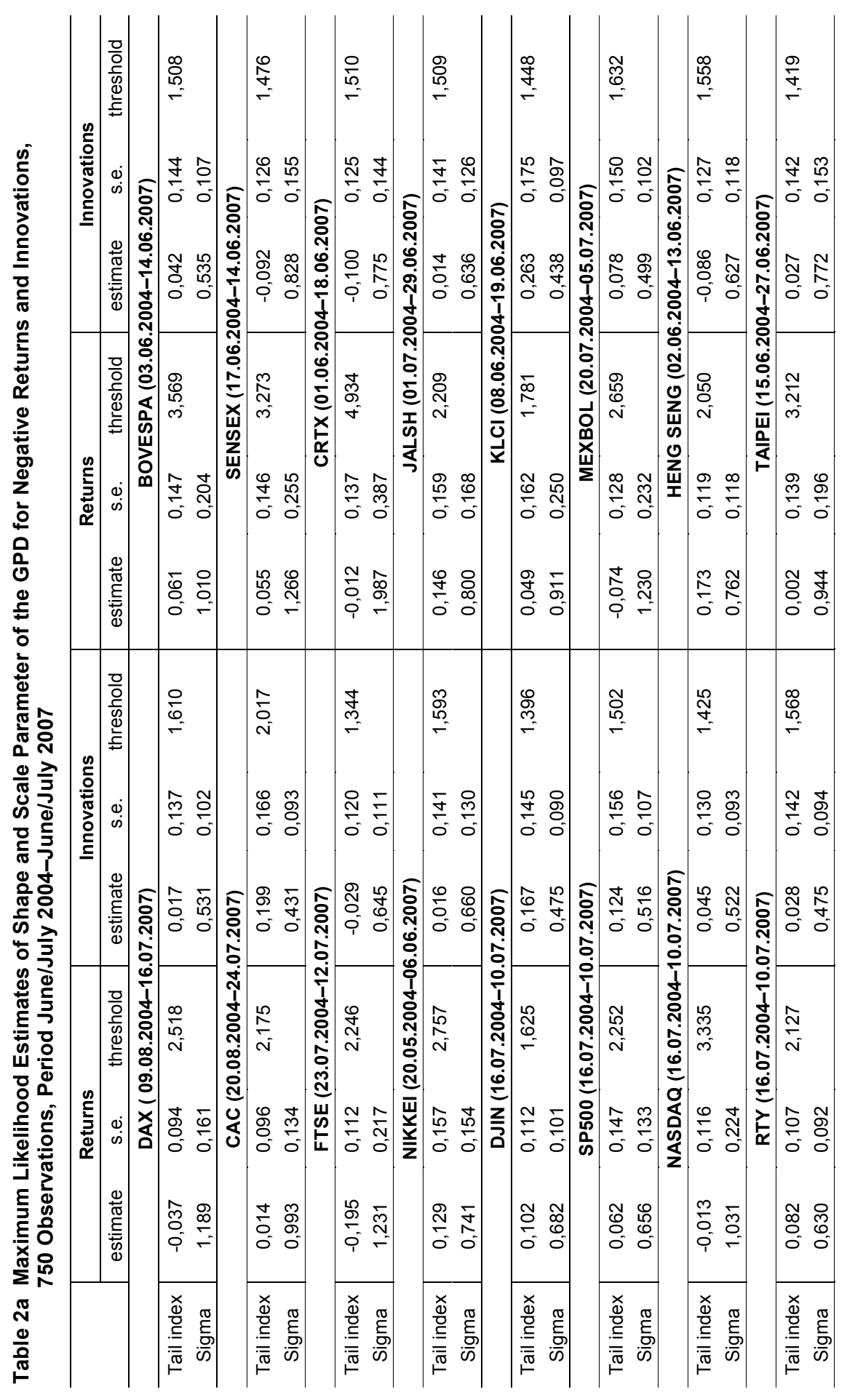




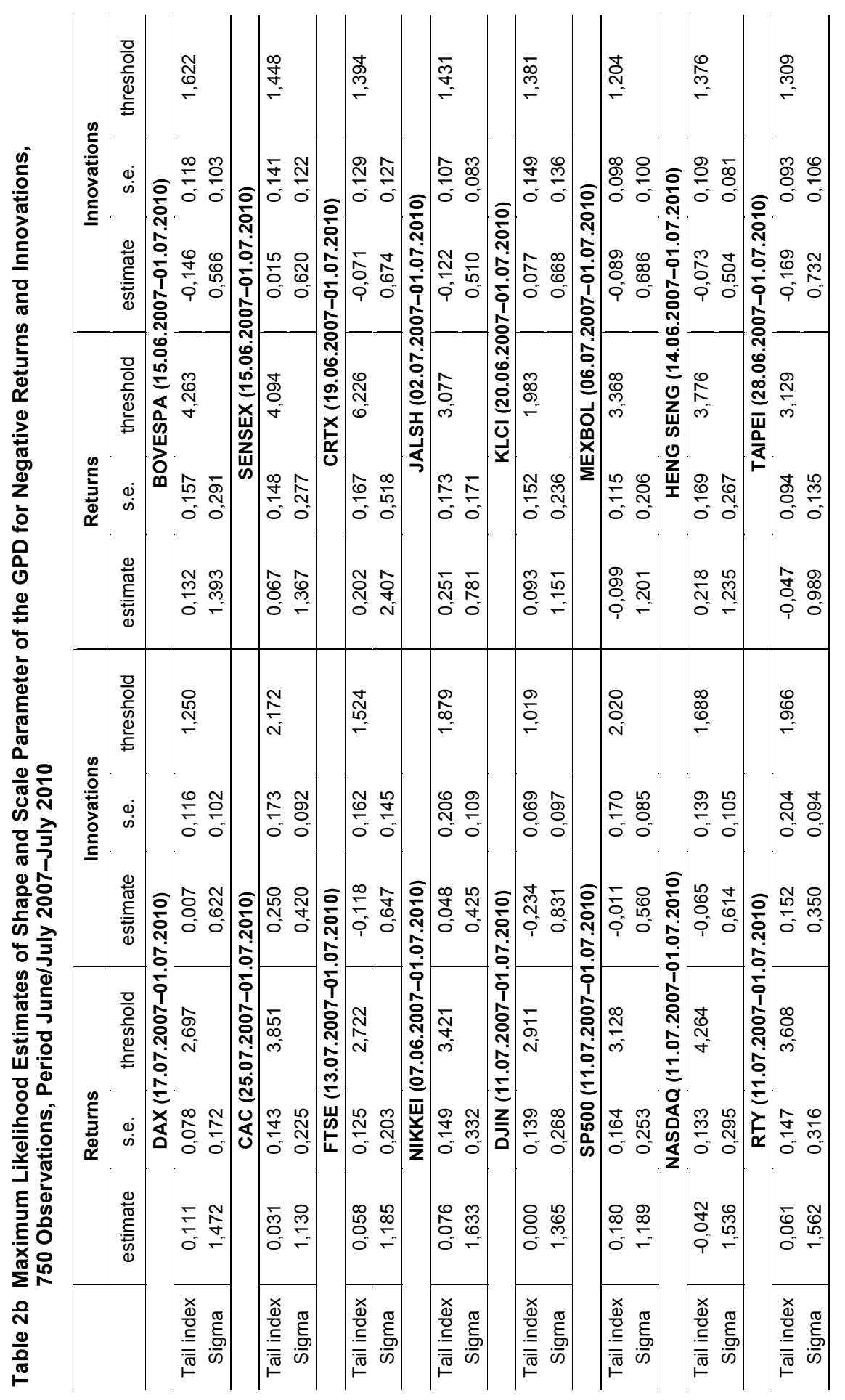


Table 3a Number of VaR Model Successes According to Kupiec and Christoffersen Independence Tests at 5 and $10 \%$ Significance Level, $99 \%$ Confidence Level, 750 Observations (June/July 2004-June/July 2007)

\begin{tabular}{|c|c|c|c|c|c|c|c|c|}
\hline \multicolumn{9}{|c|}{ Developed markets (8) } \\
\hline & HS 250 & HS 500 & MHS 250 & MHS 500 & KHS 250 & KHS 500 & $\begin{array}{c}\text { BRW } \\
\lambda=0,97\end{array}$ & $\begin{array}{c}\text { BRW } \\
\lambda=0,99\end{array}$ \\
\hline Kupiec test* & 5 & 8 & 8 & 8 & 8 & 8 & 2 & 7 \\
\hline Kupiec test ${ }^{\star *}$ & 2 & 8 & 8 & 8 & 8 & 8 & 1 & 7 \\
\hline \multirow[t]{2}{*}{ Independence ${ }^{\star \star *}$} & 8 & 7 & 7 & 7 & 7 & 7 & 7 & 5 \\
\hline & VCV & $\begin{array}{c}\text { Risk } \\
\text { Metrics }\end{array}$ & GARCH & FHS & $\mathrm{HW}$ & $\begin{array}{c}\text { EVT } \\
\text { GARCH }\end{array}$ & GPD & \\
\hline Kupiec test ${ }^{*}$ & 2 & 1 & 6 & 8 & 2 & 8 & 8 & \\
\hline Kupiec test ${ }^{\star *}$ & 2 & 1 & 6 & 8 & 1 & 8 & 8 & \\
\hline Independence ${ }^{\star * *}$ & 7 & 3 & 8 & 8 & 6 & 8 & 8 & \\
\hline \multicolumn{9}{|c|}{ Emerging markets (8) } \\
\hline & HS 250 & HS 500 & MHS 250 & MHS 500 & KHS 250 & KHS 500 & $\begin{array}{c}\text { BRW } \\
\lambda=0,97\end{array}$ & $\begin{array}{c}\text { BRW } \\
\lambda=0,99\end{array}$ \\
\hline Kupiec test* & 7 & 6 & 8 & 8 & 8 & 8 & 3 & 8 \\
\hline Kupiec test ${ }^{\star *}$ & 5 & 6 & 8 & 8 & 8 & 7 & 2 & 6 \\
\hline \multirow[t]{2}{*}{ Independence ${ }^{\star \star *}$} & 6 & 6 & 6 & 6 & 7 & 5 & 8 & 7 \\
\hline & VCV & $\begin{array}{c}\text { Risk } \\
\text { Metrics }\end{array}$ & GARCH & FHS & $\mathrm{HW}$ & $\begin{array}{c}\text { EVT } \\
\text { GARCH }\end{array}$ & GPD & \\
\hline Kupiec test ${ }^{\star}$ & 2 & 0 & 5 & 8 & 3 & 8 & 8 & \\
\hline Kupiec test ${ }^{\star *}$ & 0 & 0 & 2 & 8 & 2 & 8 & 8 & \\
\hline Independence ${ }^{* * *}$ & 5 & 5 & 8 & 8 & 7 & 8 & 8 & \\
\hline
\end{tabular}

Notes: * $5 \%$ significance level; ${ }^{* *} 10 \%$ significance level; ${ }^{* *}$ Christoffersen (1998) independence tests at $5 \%$ significance level.

HS $n$-historical simulation model with $n$ day moving window; MHS $n$ - "mirrored" historical simulation model with $n$ day moving window; KHS $n$-kernel historical approach with $n$ day moving window; BRW—Boudoukh, Richardson, Whitelaw (time weighted) simulation model, $\lambda$-decay factor; VCVnormally distributed variance-covariance model; GARCH-parametric $\operatorname{EGARCH}(p, q)$ model with GED or T distributed innovations; FHS-Filtered historical simulation Barone-Adesi et. al. (1999); HW-HullWhite (1998) model; EVT-GARCH-McNeil, Frey (2002) conditional EVT model, GPD—unconditional EVT model using Generalized Pareto distribution. 
Table 3b Number of VaR Model Successes According to Kupiec and Christoffersen Independence Tests at 5 and $10 \%$ Significance Level, 99\% Confidence Level, 750 observations (June/July 2007-July 2010)

\begin{tabular}{|c|c|c|c|c|c|c|c|c|}
\hline \multicolumn{9}{|c|}{ Developed markets (8) } \\
\hline & HS 250 & HS 500 & MHS 250 & MHS 500 & KHS 250 & KHS 500 & $\begin{array}{c}\text { BRW } \\
\lambda=0,97\end{array}$ & $\begin{array}{c}\text { BRW } \\
\lambda=0,99\end{array}$ \\
\hline Kupiec test* & 0 & 0 & 1 & 1 & 1 & 1 & 0 & 3 \\
\hline Kupiec test ${ }^{\star *}$ & 0 & 0 & 1 & 0 & 1 & 0 & 0 & 2 \\
\hline \multirow[t]{2}{*}{ Independence ${ }^{* * *}$} & 7 & 6 & 8 & 8 & 8 & 7 & 8 & 8 \\
\hline & VCV & $\begin{array}{c}\text { Risk } \\
\text { Metrics }\end{array}$ & GARCH & FHS & $\mathrm{HW}$ & $\begin{array}{c}\text { EVT } \\
\text { GARCH }\end{array}$ & $\begin{array}{c}\text { EVT } \\
\text { GARCH (L) }\end{array}$ & GPD \\
\hline Kupiec test* & 0 & 0 & 1 & 3 & 7 & 2 & 8 & 8 \\
\hline Kupiec test ${ }^{\star *}$ & 0 & 0 & 1 & 0 & 7 & 2 & 8 & 7 \\
\hline Independence ${ }^{\star \star *}$ & 6 & 8 & 8 & 8 & 5 & 8 & 7 & 8 \\
\hline \multicolumn{9}{|c|}{ Emerging markets (8) } \\
\hline & HS 250 & HS 500 & MHS 250 & MHS 500 & KHS 250 & KHS 500 & $\begin{array}{c}\text { BRW } \\
\lambda=0,97\end{array}$ & $\begin{array}{c}\text { BRW } \\
\lambda=0,99\end{array}$ \\
\hline Kupiec test ${ }^{*}$ & 1 & 1 & 8 & 6 & 5 & 1 & 0 & 5 \\
\hline Kupiec test ${ }^{\star *}$ & 1 & 1 & 7 & 6 & 2 & 1 & 0 & 5 \\
\hline \multirow[t]{2}{*}{ Independence ${ }^{\star * *}$} & 6 & 5 & 7 & 6 & 7 & 6 & 7 & 6 \\
\hline & VCV & $\begin{array}{c}\text { Risk } \\
\text { Metrics }\end{array}$ & $\mathrm{GARCH}$ & FHS & $\mathrm{HW}$ & $\begin{array}{c}\text { EVT } \\
\text { GARCH }\end{array}$ & $\begin{array}{c}\text { EVT } \\
\text { GARCH (L) }\end{array}$ & GPD \\
\hline Kupiec test ${ }^{*}$ & 0 & 0 & 4 & 6 & 5 & 3 & 8 & 6 \\
\hline Kupiec test ${ }^{\star *}$ & 0 & 0 & 4 & 5 & 4 & 3 & 6 & 6 \\
\hline Independence ${ }^{\star \star \star}$ & 6 & 6 & 8 & 8 & 5 & 8 & 8 & 7 \\
\hline
\end{tabular}

Notes: * $5 \%$ significance level; ${ }^{* *} 10 \%$ significance level; ${ }^{* *}$ Christoffersen (1998) independence tests at $5 \%$ significance level. 
Table 4a VaR Ranking According to Minimal Average VaR Values, 99\% Confidence Level, 750 Observations (June/July 2004-June/July2007)

\begin{tabular}{|c|c|c|c|c|c|c|c|c|}
\hline & S\&P 500 & DJIN & NASDAQ & RTY & NIKKEI & FTSE & DAX & CAC \\
\hline HS 250 & 1,55 & 1,57 & 2,07 & 2,40 & 2,85 & 1,81 & 2,35 & 2,25 \\
\hline HS 500 & 1,70 & 1,73 & 2,35 & 2,50 & 3,12 & 1,98 & 2,85 & 2,51 \\
\hline MHS 250 & 1,72 & 1,76 & 2,26 & 2,66 & 3,05 & 1,94 & 2,48 & 2,35 \\
\hline MHS 500 & 2,00 & 2,04 & 2,64 & 2,69 & 3,22 & 2,30 & 3,08 & 2,81 \\
\hline KHS 250 & 1,63 & 1,66 & 2,23 & 2,59 & 3,06 & 1,92 & 2,53 & 2,37 \\
\hline KHS 500 & 1,78 & 1,78 & 2,44 & 2,59 & 3,26 & 2,08 & 2,93 & 2,60 \\
\hline $\begin{array}{l}\text { BRW } \\
\lambda=0,97\end{array}$ & & & 2,01 & $2,30^{*}$ & 2,67 & 1,62 & 2,21 & 2,02 \\
\hline $\begin{array}{l}\text { BRW } \\
\lambda=0,99\end{array}$ & $1,60^{* *}$ & $1,62^{* *}$ & 2,13 & 2,46 & 2,97 & 1,85 & 2,44 & 2,33 \\
\hline $\begin{array}{l}\text { Normal } \\
\text { VCV }\end{array}$ & 1,51 & 1,49 & 2,11 & 2,47 & 2,56 & 1,51 & 2,04 & 1,86 \\
\hline $\begin{array}{l}\text { Risk } \\
\text { Metrics }\end{array}$ & $1,46^{*}$ & $1,43^{*}$ & $1,95^{\star *}$ & 2,32 & $2,33^{*}$ & $1,47^{*}$ & $1,93^{*}$ & 1,79 \\
\hline GARCH & 1,52 & 1,49 & 1,99 & 2,38 & $2,48^{* *}$ & $1,51^{* *}$ & 2,00 ** & $1,86^{*}$ \\
\hline $\mathrm{HW}$ & 1,76 & 1,70 & 2,10 & 2,59 & 3,38 & 2,24 & 2,60 & 2,54 \\
\hline FHS & 1,81 & 1,75 & 2,30 & 2,67 & 2,68 & 1,83 & 3,07 & 2,06 \\
\hline $\begin{array}{l}\text { EVT } \\
\text { GARCH }\end{array}$ & 2,07 & 2,06 & 2,24 & 2,37 & 3,34 & 1,78 & 2,16 & 2,73 \\
\hline \multirow[t]{2}{*}{ GDP } & 3,44 & 3,29 & 3,90 & 3,45 & 4,22 & 2,84 & 3,44 & 3,28 \\
\hline & JALSH & BOVE & MEXBOL & $\mathrm{KLCl}$ & CRTX & SENSEX & H SENG & TAIPEI \\
\hline HS 250 & 2,65 & 3,94 & 2,92 & 1,53 & 6,04 & 3,68 & 2,37 & 3,39 \\
\hline HS 500 & 2,51 & 4,07 & 2,74 & 1,58 & 5,82 & 3,58 & 2,38 & 3,42 \\
\hline MHS 250 & 3,26 & 4,35 & 3,40 & 1,82 & 6,92 & 4,37 & 2,54 & 3,63 \\
\hline MHS 500 & 3,15 & 4,61 & 3,28 & 1,96 & 6,50 & 4,01 & 2,71 & 4,07 \\
\hline KHS 250 & 2,85 & 4,23 & 3,12 & 1,64 & 6,56 & 4,03 & 2,51 & 3,58 \\
\hline KHS 500 & 2,75 & 4,23 & 2,83 & 1,66 & 6,06 & 3,74 & 2,47 & 3,57 \\
\hline $\begin{array}{l}\text { BRW } \\
\lambda=0,97\end{array}$ & 2,41 & 3,75 & 2,64 & 1,45 & 5,52 & 3,35 & 2,27 & 2,85 \\
\hline $\begin{array}{l}\text { BRW } \\
\lambda=0,99\end{array}$ & 2,69 & 4,08 & 2,94 & 1,59 & 6,28 & 3,83 & 2,47 & 3,41 \\
\hline $\begin{array}{l}\text { Normal } \\
\text { VCV }\end{array}$ & $2,32^{*}$ & 3,64 & 2,53 & 1,35 & 4,85 & 3,18 & 2,05 & $2,54^{* *}$ \\
\hline $\begin{array}{l}\text { Risk } \\
\text { Metrics }\end{array}$ & 2,24 & $3,37^{*}$ & $2,47^{*}$ & $1,31^{*}$ & $4,45^{\star}$ & $2,79^{\star}$ & $1,95^{\star}$ & $2,18^{*}$ \\
\hline GARCH & 2,33 & $3,49^{* *}$ & $2,59^{* *}$ & $1,36^{* *}$ & 4,62 & $2,84^{* *}$ & $2,08^{* *}$ & 2,23 \\
\hline $\mathrm{HW}$ & 3,80 & 4,20 & 4,33 & 2,29 & 7,06 & 4,93 & 2,71 & 3,08 \\
\hline FHS & $2,61^{\text {** }}$ & 4,08 & 3,00 & 1,75 & $5,37^{* *}$ & 3,51 & 2,31 & 2,74 \\
\hline $\begin{array}{l}\text { EVT } \\
\text { GARCH }\end{array}$ & 3,00 & 4,03 & 3,05 & 2,24 & 5,65 & 3,77 & 2,11 & 3,58 \\
\hline GDP & 5,18 & 5,29 & 4,74 & 4,66 & 8,80 & 6,56 & 4,00 & 4,31 \\
\hline
\end{tabular}

Notes: Grey areas mark VaR models which satisfied the Kupiec (1995) and the Christoffersen (1998) independence test at $5 \%$ significance level, ${ }^{*}$ lowest average VaR value, ${ }^{* *}$ lowest average VaR value for a model which satisfies the Kupiec and the Christoffersen independence test. 
Table 4b VaR Ranking According to Minimal Average VaR Values, $99 \%$ Confidence Level, 750 Observations (June/July 2007-July 2010)

\begin{tabular}{|c|c|c|c|c|c|c|c|c|}
\hline & S\&P 500 & DJIN & NASDAQ & RTY & NIKKEI & FTSE & DAX & CAC \\
\hline HS 250 & 4,98 & 4,40 & 4,61 & 5,40 & 5,87 & 4,43 & 4,67 & 4,74 \\
\hline HS 500 & 4,70 & 4,29 & 4,47 & 5,43 & 5,46 & 4,39 & 4,61 & 4,99 \\
\hline MHS 250 & 5,53 & 4,88 & 5,52 & 5,94 & 6,10 & 5,29 & 5,54 & 5,75 \\
\hline MHS 500 & 5,69 & 5,22 & 5,15 & 6,14 & 6,87 & 5,80 & 5,47 & 6,18 \\
\hline KHS 250 & 5,15 & 4,57 & 4,99 & 5,76 & 6,05 & 4,85 & 4,87 & 5,03 \\
\hline KHS 500 & 4,98 & 4,43 & 4,64 & 5,62 & 5,77 & 4,59 & 4,84 & 5,07 \\
\hline $\begin{array}{l}\text { BRW } \\
\lambda=0,97\end{array}$ & 4,06 & 3,60 & 3,94 & 4,56 & 4,47 & 3,80 & 3,92 & 4,09 \\
\hline $\begin{array}{l}\text { BRW } \\
\lambda=0,99\end{array}$ & 4,92 & 4,37 & 4,72 & 5,40 & 5,65 & 4,55 & 4,65 & 4,75 \\
\hline $\begin{array}{l}\text { Normal } \\
\text { VCV }\end{array}$ & 4,07 & 3,70 & 4,19 & 4,97 & 4,55 & 3,84 & 4,00 & 4,20 \\
\hline $\begin{array}{l}\text { Risk } \\
\text { Metrics }\end{array}$ & 3,90 & 3,54 & 4,05 & 4,86 & 4,32 & 3,72 & 3,86 & 4,15 \\
\hline GARCH & 4,00 & 3,65 & 4,16 & 4,90 & 4,32 & 3,75 & 3,94 & 4,19 \\
\hline $\mathrm{HW}$ & 13,70 & 12,38 & 11,18 & 14,08 & 12,75 & 10,76 & 10,20 & 10,69 \\
\hline FHS & 3,85 & 3,68 & 3,88 & $4,73^{* *}$ & $4,20^{* *}$ & 3,67 & $3,84^{* *}$ & 3,93 \\
\hline $\begin{array}{l}\text { EVT } \\
\text { GARCH }\end{array}$ & 4,32 & 3,62 & 4,35 & 4,91 & 4,06 & 3,70 & 4,81 & 6,44 \\
\hline $\begin{array}{l}\text { EVT } \\
\text { GARCH (L) }\end{array}$ & $4,89^{* *}$ & $5,00^{* *}$ & $4,91^{* *}$ & 5,27 & 5,03 & $3,78^{* *}$ & 4,85 & 5,08 \\
\hline \multirow[t]{2}{*}{ GPD } & 8,43 & 6,23 & 6,37 & 8,22 & 8,92 & 6,19 & 5,23 & $5,53^{* *}$ \\
\hline & JALSH & BOVE & MEXBOL & $\mathrm{KLCl}$ & CRTX & SENSEX & H SENG & TAIPEI \\
\hline HS 250 & 4,25 & 5,83 & 4,28 & $2,96^{* *}$ & 9,37 & 5,27 & 5,62 & 4,41 \\
\hline HS 500 & 4,29 & 6,10 & 4,67 & 3,13 & 9,52 & 5,44 & 5,67 & 4,37 \\
\hline MHS 250 & 4,80 & 7,24 & 5,18 & 3,23 & 10,53 & 5,96 & 7,06 & 4,84 \\
\hline MHS 500 & 5,21 & 7,22 & 5,44 & 3,35 & 12,16 & 6,22 & 7,09 & 4,91 \\
\hline KHS 250 & 4,55 & 6,34 & 4,61 & 3,09 & 9,90 & 5,62 & 5,98 & 4,64 \\
\hline KHS 500 & 4,58 & 6,22 & 4,78 & 3,22 & 10,31 & 5,71 & 5,92 & 4,54 \\
\hline $\begin{array}{l}\text { BRW } \\
\lambda=0,97\end{array}$ & 3,60 & 5,06 & 3,93 & 2,41 & 7,76 & 4,73 & 4,71 & 4,11 \\
\hline $\begin{array}{l}\text { BRW } \\
\lambda=0,99\end{array}$ & 4,22 & 6,06 & 4,57 & 2,97 & 9,30 & 5,39 & 5,55 & 4,52 \\
\hline $\begin{array}{l}\text { Normal } \\
\text { VCV }\end{array}$ & 3,87 & 5,29 & 4,06 & 2,46 & 7,56 & 4,98 & 5,28 & 3,86 \\
\hline $\begin{array}{l}\text { Risk } \\
\text { Metrics }\end{array}$ & 3,70 & 4,96 & 3,75 & 2,20 & 7,27 & 4,66 & 5,02 & 3,81 \\
\hline GARCH & 3,79 & $5,14^{* *}$ & 3,96 & 2,26 & 7,31 & $4,79^{* *}$ & $5,11^{* *}$ & 3,98 \\
\hline $\mathrm{HW}$ & 7,81 & 9,98 & 8,40 & 5,28 & 21,66 & 11,39 & 13,04 & 8,21 \\
\hline FHS & $3,87^{\star *}$ & 5,36 & 4,25 & 2,59 & $\mathbf{7 , 7 1 ^ { * * }}$ & 5,26 & 4,78 & $4,34^{\star *}$ \\
\hline $\begin{array}{l}\text { EVT } \\
\text { GARCH }\end{array}$ & 2,90 & 3,99 & 4,34 & 3,54 & 8,24 & 6,02 & 4,28 & 3,97 \\
\hline $\begin{array}{l}\text { EVT } \\
\text { GARCH (L) }\end{array}$ & 4,07 & 5,52 & $5,09^{* *}$ & 3,54 & 8,71 & 7,49 & 5,29 & 4,65 \\
\hline GPD & 6,69 & 8,74 & 4,39 & 6,56 & 18,11 & 7,30 & 9,68 & 4,03 \\
\hline
\end{tabular}

Notes: See Table 4a. 
Table 5a VaR Ranking According to Minimal Lopez Size Adjusted Score, 99\% Confidence Level, 750 Observations (June/July 2004-June/July2007)

\begin{tabular}{|c|c|c|c|c|c|c|c|c|}
\hline & S\&P 500 & DJIN & NASDAQ & RTY & NIKKEI & FTSE & DAX & CAC \\
\hline HS 250 & 4,05 & 3,04 & 1,04 & 1,05 & 4,06 & 4,05 & 3,05 & 3,05 \\
\hline HS 500 & 1,04 & $0,03^{* *}$ & $-1,97$ & 0,04 & 1,04 & 0,06 & 0,04 & 0,05 \\
\hline MHS 250 & $-0,98$ & $-0,98$ & $-2,97$ & $0,03^{* *}$ & $-0,96$ & $0,04^{* *}$ & $-1,97$ & $-1,97$ \\
\hline MHS 500 & $-2,98$ & $-1,98$ & $-3,98$ & $-0,97$ & $-1,97$ & 0,04 & $-1,97$ & $0,03^{* *}$ \\
\hline $\mathrm{KHS} 250$ & 2,04 & 1,03 & $-1,97$ & $-1,97$ & 1,05 & 1,04 & 1,03 & $-0,96$ \\
\hline KHS 500 & $-0,97^{* *}$ & $-0,97$ & $-2,98$ & 0,04 & $-0,96$ & 0,05 & $0,03^{* *}$ & 0,04 \\
\hline $\begin{array}{l}\text { BRW } \\
\lambda=0,97\end{array}$ & 7,06 & 5,06 & 4,06 & 2,06 & 6,08 & 6,05 & 3,06 & 8,06 \\
\hline $\begin{array}{l}\text { BRW } \\
\lambda=0,99\end{array}$ & 2,03 & $-0,96$ & $-0,97$ & $-0,96$ & 0,05 & 5,04 & 0,04 & 0,03 \\
\hline $\begin{array}{l}\text { Normal } \\
\text { VCV }\end{array}$ & 4,05 & 5,05 & $0,04^{* *}$ & 1,05 & 9,10 & 11,08 & 9,08 & 9,08 \\
\hline $\begin{array}{l}\text { Risk } \\
\text { Metrics }\end{array}$ & 9,06 & 7,07 & 2,06 & 5,06 & 7,09 & 8,07 & 7,09 & 7,07 \\
\hline GARCH & 4,04 & 4,05 & 1,04 & 0,04 & 2,06 & 2,04 & 2,04 & 2,05 \\
\hline HW & 9,06 & 8,07 & 15,08 & 6,08 & 7,06 & 3,02 & 5,06 & 1,04 \\
\hline FHS & $-4,98$ & $-1,97$ & $-3,97$ & $-1,97$ & $-0,96^{\star *}$ & $-2,98$ & $-6,99$ & $-1,97$ \\
\hline $\begin{array}{l}\text { EVT } \\
\text { GARCH }\end{array}$ & $-6,98$ & $-5,98$ & $-2,97$ & 0,05 & $-5,98$ & $-1,98$ & $-1,97$ & $-6,99$ \\
\hline \multirow[t]{2}{*}{ GPD } & $-7,00$ & $-7,00$ & $-7,00$ & $-7,00$ & $-7,00$ & $-7,00$ & $-7,00$ & $-7,00$ \\
\hline & JALSH & BOVE & MEXBOL & $\mathrm{KLCl}$ & CRTX & SENSEX & H SENG & TAIPEI \\
\hline HS 250 & 6,11 & 2,07 & 1,09 & 3,10 & 0,16 & 2,11 & 3,05 & $-0,94^{* *}$ \\
\hline HS 500 & 5,13 & $-2,94$ & 2,11 & 4,11 & $-0,86$ & 2,12 & 1,05 & $-2,96$ \\
\hline MHS 250 & 2,07 & $-2,95$ & $-1,95$ & 0,07 & $-1,88$ & $-1,92$ & 1,04 & $-0,95$ \\
\hline MHS 500 & $0,07^{\star *}$ & $-4,96$ & $-0,94$ & $-1,93$ & $-2,90$ & 0,09 & $-0,97$ & $-2,97$ \\
\hline KHS 250 & 2,09 & $-1,95$ & $-0,93$ & $2,08^{* *}$ & $-1,87$ & $-0,92$ & 2,04 & $-1,95$ \\
\hline KHS 500 & 3,12 & $-2,95$ & 1,10 & 0,10 & $-0,87$ & 1,11 & 1,04 & $-2,97$ \\
\hline $\begin{array}{l}\text { BRW } \\
\lambda=0,97\end{array}$ & 9,11 & 4,09 & 6,09 & 5,08 & 2,18 & 2,11 & 4,07 & 3,11 \\
\hline $\begin{array}{l}\text { BRW } \\
\lambda=0,99\end{array}$ & 3,09 & $0,06^{* *}$ & 3,07 & 1,07 & 0,11 & 0,08 & $0,04^{* *}$ & $-1,96$ \\
\hline $\begin{array}{l}\text { Normal } \\
\text { VCV }\end{array}$ & 9,16 & 3,08 & 7,12 & 6,12 & 9,29 & 11,18 & 10,09 & 3,11 \\
\hline $\begin{array}{l}\text { Risk } \\
\text { Metrics }\end{array}$ & 7,10 & 7,11 & 10,11 & 7,08 & 9,24 & 10,16 & 6,07 & 5,12 \\
\hline GARCH & 5,09 & 2,07 & $-0,94$ & 3,06 & 6,16 & 3,11 & 3,05 & 5,11 \\
\hline $\mathrm{HW}$ & 4,04 & 4,11 & $0,05^{* *}$ & 6,04 & 1,10 & 3,05 & 5,04 & 6,06 \\
\hline FHS & 2,05 & $-3,96$ & $-3,96$ & $-2,97$ & $0,08^{\star *}$ & 0,05 & $-1,97$ & 1,05 \\
\hline $\begin{array}{l}\text { EVT } \\
\text { GARCH }\end{array}$ & $-2,97$ & $-3,96$ & $-3,96$ & $-6,00$ & $-3,94$ & $0,03^{* *}$ & 1,05 & $-5,00$ \\
\hline GPD & $-6,98$ & $-6,98$ & $-6,99$ & $-7,00$ & $-5,97$ & $-7,00$ & $-7,00$ & $-7,00$ \\
\hline
\end{tabular}

Notes: Reported figures represent Lopez (1998) test scores. Grey areas mark VaR models satisfying the Kupiec (1995) and the Christoffersen (1998) independence test at 5\% significance level, ${ }^{* *}$ lowest Lopez score i.e. smallest deviation from expected values. 
Table 5b VaR Ranking According to Minimal Lopez Size Adjusted Score, 99\% Confidence Level, 750 Observations (June/July 2007-July 2010)

\begin{tabular}{|c|c|c|c|c|c|c|c|c|}
\hline & S\&P 500 & DJIN & NASDAQ & RTY & NIKKEI & FTSE & DAX & CAC \\
\hline HS 250 & 15,25 & 14,23 & 16,26 & 14,30 & 8,29 & 10,22 & 6,17 & 10,23 \\
\hline HS 500 & 21,36 & 18,30 & 22,31 & 15,37 & 11,37 & 9,27 & 8,26 & 9,28 \\
\hline MHS 250 & 10,18 & 10,15 & 8,15 & 6,20 & 4,23 & 4,15 & 1,12 & 6,16 \\
\hline MHS 500 & 14,26 & 11,22 & 10,21 & 6,25 & 8,32 & 5,21 & 3,18 & 5,21 \\
\hline KHS 250 & 11,21 & 10,19 & 12,20 & 8,23 & 4,24 & 5,18 & 2,14 & 7,19 \\
\hline KHS 500 & 20,33 & 17,27 & 15,27 & 14,33 & 8,34 & 8,24 & 3,24 & 7,26 \\
\hline $\begin{array}{l}\text { BRW } \\
\lambda=0,97\end{array}$ & 16,24 & 11,19 & 17,22 & 15,27 & 9,28 & 9,22 & 11,18 & 12,22 \\
\hline $\begin{array}{l}\text { BRW } \\
\lambda=0,99\end{array}$ & 11,21 & 7,17 & 12,20 & 9,24 & 3,24 & 2,19 & 2,15 & 5,18 \\
\hline $\begin{array}{l}\text { Normal } \\
\text { VCV }\end{array}$ & 29,41 & 27,34 & 22,31 & 22,39 & 20,41 & 20,32 & 13,29 & 18,35 \\
\hline $\begin{array}{l}\text { Risk } \\
\text { Metrics }\end{array}$ & 16,14 & 11,12 & 14,13 & 10,09 & 7,18 & 11,14 & 9,12 & 5,13 \\
\hline GARCH & 9,09 & 8,08 & 10,09 & 5,06 & 2,10 & 7,12 & 4,10 & 6,10 \\
\hline $\mathrm{HW}$ & $-1,97$ & 4,04 & $1,05^{\star *}$ & $-1,96$ & 2,05 & $0,03^{* *}$ & $1,05^{* *}$ & 1,06 \\
\hline FHS & 15,11 & 8,07 & 14,13 & 3,67 & 3,11 & 10,14 & 3,47 & 8,13 \\
\hline $\begin{array}{l}\text { EVT } \\
\text { GARCH }\end{array}$ & 4,06 & 8,08 & 4,07 & 5,06 & 4,12 & 7,13 & $-5,95$ & $-6,98$ \\
\hline $\begin{array}{l}\text { EVT } \\
\text { GARCH (L) }\end{array}$ & $-2,97^{\star *}$ & $-6,00$ & $-3,96$ & $0,03^{\star *}$ & $-1,94^{* *}$ & 3,09 & $-5,95$ & $-4,95$ \\
\hline \multirow[t]{2}{*}{ GPD } & $-4,97$ & $-3,94^{* *}$ & $-3,91$ & $-4,93$ & $-3,94$ & $-4,94$ & 1,11 & $1,12^{* *}$ \\
\hline & JALSH & BOVE & MEXBOL & $\mathrm{KLCl}$ & CRTX & SENSEX & H SENG & TAIPEI \\
\hline HS 250 & 6,15 & 7,24 & 10,14 & 1,09 & 7,55 & 4,16 & 13,25 & 6,11 \\
\hline HS 500 & 5,16 & 6,29 & 5,13 & 1,12 & 7,74 & 7,20 & 18,37 & 6,13 \\
\hline MHS 250 & 2,11 & $0,15^{\star *}$ & 2,07 & $0,08^{* *}$ & 3,41 & 1,12 & 2,13 & 2,08 \\
\hline MHS 500 & 0,10 & 0,20 & $-1,94$ & 1,10 & 2,57 & 2,13 & 11,22 & 4,09 \\
\hline KHS 250 & 3,12 & 4,19 & 4,09 & 0,09 & 3,46 & 3,12 & 7,17 & 1,09 \\
\hline KHS 500 & 4,14 & 5,27 & 5,11 & 2,11 & 6,67 & 7,18 & 17,33 & 5,11 \\
\hline $\begin{array}{l}\text { BRW } \\
\lambda=0,97\end{array}$ & 8,17 & 11,25 & 8,13 & 7,14 & 12,48 & 8,19 & 13,27 & 10,14 \\
\hline $\begin{array}{l}A=0,99 \\
\lambda=0\end{array}$ & 2,14 & 4,19 & 1,08 & 1,09 & 5,41 & 2,13 & 9,21 & $0,09^{* *}$ \\
\hline $\begin{array}{l}\text { Normal } \\
\text { VCV }\end{array}$ & 13,22 & 13,32 & 16,21 & 8,18 & 16,76 & 15,26 & 18,33 & 17,25 \\
\hline $\begin{array}{l}\text { Risk } \\
\text { Metrics }\end{array}$ & 12,11 & 10,16 & 11,16 & 11,17 & 10,37 & 12,19 & 5,17 & 14,18 \\
\hline GARCH & 4,06 & 2,09 & 8,13 & 4,11 & 2,26 & 2,12 & 2,09 & 9,11 \\
\hline $\mathrm{HW}$ & 4,04 & 6,12 & $0,06^{* *}$ & 3,03 & 0,07 & 4,08 & $1,05^{* *}$ & 2,08 \\
\hline FHS & $0,03^{* \star}$ & 1,07 & 7,09 & $-2,92$ & 1,22 & $-0,91^{* *}$ & 7,13 & 3,07 \\
\hline $\begin{array}{l}\text { EVT } \\
\text { GARCH }\end{array}$ & 27,22 & 26,32 & 7,08 & $-5,95$ & 0,17 & $-1,95$ & 11,21 & 9,12 \\
\hline $\begin{array}{l}\text { EVT } \\
\text { GARCH (L) }\end{array}$ & 3,05 & $-0,94$ & $-1,98$ & $-5,95$ & $0,16^{* *}$ & $-5,98$ & 3,10 & 1,06 \\
\hline GPD & $-5,99$ & $-4,94$ & 8,14 & $-6,97$ & $-5,95$ & $-3,95$ & $-6,96$ & 9,14 \\
\hline
\end{tabular}

Notes: See Table 5a. 
Table 6a Ranking of ES Model According to Modified Blanco-Ihle Error Statistic, 99\% Confidence Level, 750 Observations (June/July 2004-June/July2007)

\begin{tabular}{|c|c|c|c|c|c|c|c|c|c|}
\hline & S\&P500 & DJIN & NASDAQ & RTY & NIKKEI & FTSE & DAX & CAC & Total \\
\hline VCV GPD & 11 & 12 & 11 & 12 & 12 & 13 & 13 & 12 & 12 \\
\hline RM GPD & 13 & 13 & 13 & 13 & 13 & 12 & 11 & 13 & 13 \\
\hline $\begin{array}{l}\text { GARCH } \\
\text { GPD }\end{array}$ & 12 & 11 & 12 & 11 & 11 & 11 & 12 & 11 & 11 \\
\hline $\begin{array}{l}\text { Bootstr } \\
\text { FHS }\end{array}$ & 4 & 4 & 5 & 1 & 1 & 5 & 1 & 4 & 2 \\
\hline $\begin{array}{l}\text { Bootstr } \\
\text { HS250 }\end{array}$ & 1 & 3 & 7 & 9 & 4 & 6 & 3 & 5 & 4 \\
\hline $\begin{array}{l}\text { Bootstr } \\
\text { HS500 }\end{array}$ & 8 & 7 & 2 & 7 & 5 & 8 & 5 & 7 & 6 \\
\hline $\begin{array}{l}\text { Bootstr } \\
\text { KHS250 }\end{array}$ & 5 & 6 & 9 & 5 & 9 & 10 & 8 & 9 & 9 \\
\hline $\begin{array}{l}\text { Bootstr } \\
\text { KHS500 }\end{array}$ & 6 & 5 & 4 & 8 & 8 & 9 & 10 & 8 & 8 \\
\hline $\begin{array}{l}\text { Bootstr } \\
\text { MHS250 }\end{array}$ & 2 & 1 & 1 & 2 & 6 & 4 & 9 & 2 & 3 \\
\hline $\begin{array}{l}\text { Bootstr } \\
\text { MHS500 }\end{array}$ & 3 & 2 & 3 & 3 & 3 & 3 & 2 & 3 & 1 \\
\hline $\begin{array}{l}\text { Bootstr } \\
\text { BRW }\end{array}$ & 7 & 8 & 6 & 6 & 7 & 7 & 6 & 6 & 7 \\
\hline $\begin{array}{l}\text { EVT } \\
\text { GARCH }\end{array}$ & 10 & 10 & 8 & 4 & 2 & 2 & 7 & 1 & 5 \\
\hline \multirow[t]{2}{*}{ GPD } & 9 & 9 & 10 & 10 & 10 & 1 & 4 & 10 & 10 \\
\hline & JALSH & BOVE & MEXBOL & $\mathrm{KLCl}$ & CRTX & SENSEX & H SENG & TAIPEI & Total \\
\hline VCV GPD & 11 & 12 & 11 & 9 & 12 & 13 & 12 & 8 & 12 \\
\hline RM GPD & 13 & 13 & 13 & 11 & 13 & 12 & 13 & 5 & 13 \\
\hline $\begin{array}{l}\text { GARCH } \\
\text { GPD }\end{array}$ & 12 & 11 & 12 & 6 & 11 & 5 & 11 & 7 & 11 \\
\hline $\begin{array}{l}\text { Bootstr } \\
\text { FHS }\end{array}$ & 1 & 1 & 2 & 1 & 3 & 6 & 1 & 3 & 1 \\
\hline $\begin{array}{l}\text { Bootstr } \\
\text { HS250 }\end{array}$ & 6 & 2 & 7 & 5 & 9 & 9 & 7 & 12 & 7 \\
\hline $\begin{array}{l}\text { Bootstr } \\
\text { HS500 }\end{array}$ & 7 & 7 & 5 & 10 & 5 & 8 & 5 & 9 & 6 \\
\hline $\begin{array}{l}\text { Bootstr } \\
\text { KHS250 }\end{array}$ & 9 & 8 & 9 & 7 & 10 & 11 & 8 & 11 & 10 \\
\hline $\begin{array}{l}\text { Bootstr } \\
\text { KHS500 }\end{array}$ & 8 & 10 & 8 & 12 & 6 & 10 & 6 & 10 & 9 \\
\hline $\begin{array}{l}\text { Bootstr } \\
\text { MHS250 }\end{array}$ & 4 & 5 & 1 & 2 & 2 & 3 & 4 & 2 & 2 \\
\hline $\begin{array}{l}\text { Bootstr } \\
\text { MHS500 }\end{array}$ & 5 & 6 & 6 & 3 & 8 & 2 & 2 & 1 & 3 \\
\hline $\begin{array}{l}\text { Bootstr } \\
\text { BRW }\end{array}$ & 10 & 3 & 3 & 8 & 7 & 7 & 9 & 13 & 8 \\
\hline $\begin{array}{l}\text { EVT } \\
\text { GARCH }\end{array}$ & 2 & 9 & 10 & 13 & 1 & 1 & 3 & 6 & 5 \\
\hline GPD & 3 & 4 & 4 & 4 & 4 & 4 & 10 & 4 & 4 \\
\hline
\end{tabular}

Note: Lowest value marks the most successful ES model. 
Table 6b Ranking of ES Model According to Modified Blanco-Ihle Error Statistic, 99\% Confidence Level, 750 Observations (June/July 2007-July2010)

\begin{tabular}{|c|c|c|c|c|c|c|c|c|c|}
\hline & S\&P500 & DJIN & NASDAQ & RTY & NIKKEI & FTSE & DAX & CAC & Total \\
\hline VCV GPD & 12 & 12 & 12 & 12 & 13 & 12 & 11 & 12 & 12 \\
\hline RM GPD & 13 & 13 & 13 & 13 & 10 & 13 & 14 & 13 & 13 \\
\hline $\begin{array}{l}\text { GARCH } \\
\text { GPD }\end{array}$ & 14 & 14 & 14 & 14 & 12 & 14 & 13 & 14 & 14 \\
\hline Bootstr FHS & 2 & 4 & 1 & 1 & 4 & 1 & 2 & 2 & 1 \\
\hline $\begin{array}{l}\text { Bootstr } \\
\text { HS250 }\end{array}$ & 6 & 6 & 5 & 6 & 8 & 6 & 5 & 7 & 6 \\
\hline $\begin{array}{l}\text { Bootstr } \\
\text { HS500 }\end{array}$ & 5 & 7 & 6 & 5 & 7 & 8 & 8 & 8 & 7 \\
\hline $\begin{array}{l}\text { Bootstr } \\
\text { KHS250 }\end{array}$ & 9 & 8 & 8 & 9 & 11 & 9 & 9 & 10 & 9 \\
\hline $\begin{array}{l}\text { Bootstr } \\
\text { KHS500 }\end{array}$ & 8 & 9 & 9 & 11 & 9 & 10 & 10 & 11 & 10 \\
\hline $\begin{array}{l}\text { Bootstr } \\
\text { MHS250 }\end{array}$ & 1 & 3 & 3 & 2 & 2 & 7 & 3 & 6 & 2 \\
\hline $\begin{array}{l}\text { Bootstr } \\
\text { MHS500 }\end{array}$ & 4 & 5 & 4 & 4 & 6 & 5 & 4 & 4 & 5 \\
\hline $\begin{array}{l}\text { Bootstr } \\
\text { BRW }\end{array}$ & 10 & 11 & 10 & 7 & 14 & 11 & 12 & 9 & 11 \\
\hline $\begin{array}{l}\text { EVT' } \\
\text { GARCH }\end{array}$ & 3 & 2 & 2 & 8 & 3 & 2 & 6 & 1 & 3 \\
\hline $\begin{array}{l}\text { EVT } \\
\text { GARCH (L) }\end{array}$ & 7 & 10 & 11 & 10 & 5 & 3 & 7 & 5 & 8 \\
\hline \multirow[t]{2}{*}{ GPD } & 11 & 1 & 7 & 3 & 1 & 4 & 1 & 3 & 4 \\
\hline & JALSH & BOVE & MEXBOL & $\mathrm{KLCl}$ & CRTX & SENSEX & H SENG & TAIPEI & Total \\
\hline VCV GPD & 11 & 13 & 14 & 10 & 12 & 13 & 13 & 13 & 12 \\
\hline RM GPD & 14 & 14 & 13 & 9 & 11 & 14 & 12 & 12 & 13 \\
\hline $\begin{array}{l}\text { GARCH } \\
\text { GPD }\end{array}$ & 13 & 12 & 12 & 14 & 9 & 12 & 14 & 14 & 14 \\
\hline Bootstr FHS & 1 & 5 & 3 & 2 & 3 & 4 & 5 & 2 & 2 \\
\hline $\begin{array}{l}\text { Bootstr } \\
\text { HS250 }\end{array}$ & 9 & 7 & 7 & 5 & 7 & 7 & 10 & 7 & 7 \\
\hline $\begin{array}{l}\text { Bootstr } \\
\text { HS500 }\end{array}$ & 6 & 8 & 6 & 13 & 8 & 3 & 9 & 8 & 8 \\
\hline $\begin{array}{l}\text { Bootstr } \\
\text { KHS250 }\end{array}$ & 10 & 10 & 8 & 6 & 10 & 9 & 11 & 9 & 9 \\
\hline $\begin{array}{l}\text { Bootstr } \\
\text { KHS500 }\end{array}$ & 8 & 11 & 10 & 12 & 13 & 6 & 8 & 10 & 11 \\
\hline $\begin{array}{l}\text { Bootstr } \\
\text { MHS250 }\end{array}$ & 2 & 3 & 5 & 4 & 5 & 10 & 2 & 5 & 4 \\
\hline $\begin{array}{l}\text { Bootstr } \\
\text { MHS500 }\end{array}$ & 4 & 6 & 2 & 3 & 4 & 5 & 6 & 6 & 5 \\
\hline $\begin{array}{l}\text { Bootstr } \\
\text { BRW }\end{array}$ & 7 & 9 & 11 & 11 & 14 & 8 & 7 & 11 & 10 \\
\hline $\begin{array}{l}\text { EVT } \\
\text { GARCH }\end{array}$ & 5 & 4 & 1 & 7 & 2 & 2 & 3 & 1 & 1 \\
\hline $\begin{array}{l}\text { EVT } \\
\text { GARCH (L) }\end{array}$ & 3 & 1 & 9 & 8 & 1 & 1 & 4 & 4 & 3 \\
\hline GPD & 12 & 2 & 4 & 1 & 6 & 11 & 1 & 3 & 6 \\
\hline
\end{tabular}

Note: See Table 6a. 
Table 7a Rankings of Simulated VaR Models Performance $(N=2.000)$ According to Lopez Size Adjusted Score

\begin{tabular}{|c|c|c|c|c|c|c|c|c|c|}
\hline & S\&P 500 & DJIN & NASDAQ & RTY & NIKKEI & FTSE & DAX & CAC & Average \\
\hline HS 250 & 5 & 5 & 6 & 6 & 5 & 6 & 4 & 6 & 12 \\
\hline HS 500 & 6 & 6 & 8 & 6 & 7 & 6 & 4 & 5 & 13 \\
\hline MHS 250 & 4 & 3 & 4 & 4 & 4 & 3 & 1 & 4 & 6 \\
\hline MHS 500 & 4 & 3 & 4 & 4 & 5 & 4 & 2 & 4 & 8 \\
\hline KHS 250 & 4 & 3 & 5 & 4 & 4 & 4 & 1 & 4 & 7 \\
\hline KHS 500 & 7 & 6 & 6 & 6 & 5 & 6 & 2 & 4 & 10 \\
\hline $\begin{array}{l}\text { BRW } \\
\lambda=0,97\end{array}$ & 6 & 4 & 7 & 6 & 6 & 6 & 5 & 6 & 11 \\
\hline $\begin{array}{l}\text { BRW } \\
\lambda=0,99\end{array}$ & 3 & 2 & 6 & 5 & 2 & 2 & 1 & 3 & 4 \\
\hline $\begin{array}{l}\text { Normal } \\
\text { VCV }\end{array}$ & 7 & 6 & 8 & 7 & 7 & 8 & 5 & 7 & 14 \\
\hline $\begin{array}{l}\text { Risk } \\
\text { Metrics }\end{array}$ & 5 & 4 & 6 & 5 & 5 & 7 & 5 & 3 & 9 \\
\hline GARCH & 2. & 3 & 5 & 3 & 1 & 5 & 3 & 3 & 5 \\
\hline$H W$ & 2 & 2 & 3 & 2 & 3 & 5 & 2 & 1 & 3 \\
\hline $\mathrm{FHS}$ & 4 & 2 & 1 & 2 & 2 & 6 & 2 & 5 & 4 \\
\hline $\begin{array}{l}\text { EVT } \\
\text { GARCH }\end{array}$ & 1 & 1 & 2 & 1 & 1 & 1 & 3 & 2 & 1 \\
\hline \multirow[t]{2}{*}{ GPD } & 3 & 1 & 3 & 2 & 2 & 1 & 1 & 1 & 2 \\
\hline & JALSH & BOVE & MEXBOL & $\mathrm{KLCl}$ & CRTX & SENSEX & H SENG & TAIPEI & Average \\
\hline HS 250 & 5 & 5 & 6 & 1 & 6 & 4 & 5 & 4 & 11 \\
\hline HS 500 & 5 & 4 & 3 & 1 & 6 & 5 & 6 & 5 & 10 \\
\hline MHS 250 & 2 & 1 & 2 & 1 & 4 & 1 & 1 & 2 & 1 \\
\hline MHS 500 & 1 & 1 & 2 & 2 & 4 & 1 & 3 & 3 & 3 \\
\hline KHS 250 & 3 & 3 & 3 & 1 & 4 & 2 & 3 & 2 & 5 \\
\hline KHS 500 & 4 & 4 & 3 & 2 & 5 & 5 & 5 & 4 & 9 \\
\hline $\begin{array}{l}\text { BRW } \\
\lambda=0,97\end{array}$ & 6 & 6 & 4 & 5 & 7 & 5 & 5 & 6 & 12 \\
\hline $\begin{array}{l}\text { BRW } \\
\lambda=0,99\end{array}$ & 2 & 3 & 1 & 2 & 5 & 2 & 4 & 1 & 4 \\
\hline $\begin{array}{l}\text { Normal } \\
\text { VCV }\end{array}$ & 7 & 6 & 6 & 5 & 7 & 6 & 6 & 7 & 14 \\
\hline $\begin{array}{l}\text { Risk } \\
\text { Metrics }\end{array}$ & 7 & 6 & 6 & 5 & 6 & 6 & 3 & 6 & 13 \\
\hline GARCH & 4 & 2 & 5 & 4 & 3 & 2 & 1 & 5 & 7 \\
\hline $\mathrm{HW}$ & 4 & 5 & 1 & 4 & 2 & 3 & 3 & 3 & 6 \\
\hline FHS & 1 & 2 & 4 & 3 & 2 & 1 & 3 & 2 & 3 \\
\hline $\begin{array}{l}\text { EVT } \\
\text { GARCH }\end{array}$ & 2 & 2 & 1 & 3 & 1 & 4 & 1 & 1 & 2 \\
\hline GPD & 5 & 3 & 5 & 3 & 5 & 3 & 2 & 4 & 8 \\
\hline
\end{tabular}

Note: Lowest value marks the most successful VaR model. 
Table 7b Rankings of Simulated ES Models Performance $(N=\mathbf{2 . 0 0 0})$ According to Modified Blanco Ihle Score

\begin{tabular}{|c|c|c|c|c|c|c|c|c|c|}
\hline & S\&P500 & DJIN & NASDAQ & RTY & NIKKEI & FTSE & DAX & CAC & Average \\
\hline $\begin{array}{l}\text { VCV } \\
\text { GPD }\end{array}$ & 8 & 7 & 7 & 8 & 7 & 7 & 5 & 6 & 10 \\
\hline RM GPD & 8 & 7 & 8 & 8 & 7 & 7 & 6 & 6 & 11 \\
\hline $\begin{array}{l}\text { GARCH } \\
\text { GPD }\end{array}$ & 8 & 7 & 8 & 8 & 7 & 7 & 6 & 6 & 11 \\
\hline $\begin{array}{l}\text { Bootstr } \\
\text { FHS }\end{array}$ & 1 & 3 & 1 & 1 & 2 & 4 & 2 & 2 & 1 \\
\hline $\begin{array}{l}\text { Bootstr } \\
\text { HS250 }\end{array}$ & 4 & 5 & 3 & 4 & 4 & 3 & 3 & 4 & 5 \\
\hline $\begin{array}{l}\text { Bootstr } \\
\text { HS500 }\end{array}$ & 3 & 5 & 3 & 4 & 4 & 5 & 4 & 4 & 6 \\
\hline $\begin{array}{l}\text { Bootstr } \\
\text { KHS250 }\end{array}$ & 5 & 6 & 5 & 7 & 6 & 5 & 4 & 5 & 7 \\
\hline $\begin{array}{l}\text { Bootstr } \\
\text { KHS500 }\end{array}$ & 5 & 6 & 5 & 7 & 5 & 6 & 4 & 5 & 8 \\
\hline $\begin{array}{l}\text { Bootstr } \\
\text { MHS250 }\end{array}$ & 1 & 2 & 2 & 2 & 1 & 2 & 2 & 4 & 1 \\
\hline $\begin{array}{l}\text { Bootstr } \\
\text { MHS500 }\end{array}$ & 3 & 4 & 2 & 3 & 3 & 2 & 2 & 3 & 4 \\
\hline $\begin{array}{l}\text { Bootstr } \\
\text { BRW }\end{array}$ & 6 & 7 & 6 & 5 & 8 & 6 & 6 & 5 & 9 \\
\hline $\begin{array}{l}\text { EVT } \\
\text { GARCH }\end{array}$ & 2 & 2 & 1 & 6 & 2 & 1 & 3 & 1 & 2 \\
\hline GPD & 7 & 1 & 4 & 2 & 1 & 1 & 1 & 2 & 3 \\
\hline & JALSH & BOVE & MEXBOL & $\mathrm{KLCl}$ & CRTX & SENSEX & H SENG & TAIPEI & Average \\
\hline $\begin{array}{l}\text { VCV } \\
\text { GPD }\end{array}$ & 6 & 6 & 6 & 4 & 6 & 6 & 5 & 7 & 9 \\
\hline RM GPD & 7 & 6 & 6 & 4 & 6 & 7 & 5 & 7 & 10 \\
\hline $\begin{array}{l}\text { GARCH } \\
\text { GPD }\end{array}$ & 7 & 6 & 6 & 6 & 5 & 6 & 5 & 7 & 10 \\
\hline $\begin{array}{l}\text { Bootstr } \\
\text { FHS }\end{array}$ & 1 & 3 & 2 & 1 & 1 & 5 & 2 & 4 & 3 \\
\hline $\begin{array}{l}\text { Bootstr } \\
\text { HS250 }\end{array}$ & 4 & 4 & 3 & 2 & 4 & 4 & 4 & 3 & 5 \\
\hline $\begin{array}{l}\text { Bootstr } \\
\text { HS500 }\end{array}$ & 3 & 4 & 3 & 5 & 4 & 2 & 4 & 3 & 5 \\
\hline $\begin{array}{l}\text { Bootstr } \\
\text { KHS250 }\end{array}$ & 5 & 5 & 4 & 2 & 6 & 4 & 4 & 5 & 6 \\
\hline $\begin{array}{l}\text { Bootstr } \\
\text { KHS500 }\end{array}$ & 4 & 5 & 4 & 5 & 7 & 3 & 3 & 5 & 7 \\
\hline $\begin{array}{l}\text { Bootstr } \\
\text { MHS250 }\end{array}$ & 1 & 2 & 2 & 2 & 2 & 3 & 2 & 3 & 2 \\
\hline $\begin{array}{l}\text { Bootstr } \\
\text { MHS500 }\end{array}$ & 2 & 4 & 1 & 1 & 2 & 3 & 3 & 1 & 2 \\
\hline $\begin{array}{l}\text { Bootstr } \\
\text { BRW }\end{array}$ & 4 & 5 & 5 & 4 & 8 & 4 & 3 & 6 & 8 \\
\hline $\begin{array}{l}\text { EVT } \\
\text { GARCH }\end{array}$ & 1 & 1 & 1 & 3 & 1 & 1 & 1 & 2 & 1 \\
\hline GPD & 6 & 1 & 2 & 1 & 3 & 5 & 1 & 2 & 4 \\
\hline
\end{tabular}

Note: Lowest value marks the most successful ES model. 


\section{REFERENCES}

Acerbi C, Nordio C, Sirtori C (2001): Expected Shortfall as a Tool for Financial Risk Management. BIS Working Paper. http://www.bis.org/bcbs/ca/acertasc.pdf

Alexander C (2001): Market Models: A Guide to Financial Data Analysis. New York, John Wiley \& Sons.

Andreev V et al. (2010): Extreme value theory and peaks over threshold model: An application to the Russian stock market. New York Science Journal, 3(6):102-107.

Angelidis T, Degiannakis S (2007): Backtesting VaR Models: An Expected Shortfall Approach. University of Crete, Department of Economics, Working Papers, no. 0701.

http://ideas.repec.org/p/crt/wpaper/0701.html

Artzner P, Delbaen F, Eber JM, Heath D (1997): Thinking coherently. Risk, 10(11):68-71.

Artzner P, Delbaen F, Eber JM, Heath D (1999): Coherent measures of risk. Mathematical Finance, 9(3):203-228.

Assaf A (2009): Extreme observations and risk assessment in the equity markets of MENA region: Tail measures and Value-at-Risk. International review of Financial Analysis, (18):109-116.

Barone-Adesi G, Giannopoulos K, Vosper L (1999): VaR without Correlations for Portfolios of Derivative Securities. The Journal of Futures Markets, 19(5):583-602.

Blanco C, Ihle G (1998): How Good is Your VaR Using Backtesting to Assess System Performance. Financial Engineering News, (August):1-2.

Butler JS, Schachter B (1998): Estimating Value-at-Risk with a Precision Measure by Combining Kernel Estimation with Historical Simulation. Review of Derivatives Research, 1(4):371-390.

Chen SX, Tang CY (2005): Nonparametric inference of Value at Risk for dependent financial returns. Journal of Financial Econometrics, 3:227-255.

Chen XC (2008): Nonparametric Estimation of Expected Shortfall. Journal of Financial Econometrics, 6(1):87-107.

Christoffersen P (1998): Evaluating Interval Forecasts. International Economic Review, 39(4):841-862.

Clark TE, McCracken MW (2001): Tests of Equal Forecast Accuracy and Encompassing for Nested Models. Journal of Econometrics, 105(1):85-110.

Committee of European Banking Supervisors (CEBS) (2009): CEBS Guidelines on aspects of the management of concentration risk under the supervisory review process (CP31).

Cotter J (2007): Extreme risk in Asian equity markets. MPRA, Paper no. 3536.

http://mpra.ub.uni-muenchen.de/3536/

Cotter J (2004): Downside Risk for European Equity Markets. Applied Financial Economics, 14(10):707-716.

Danielsson J, Vries C de (1997): Tail Index and Quantile Estimation with Very High Frequency Data. Journal of Empirical Finance, (2-3):241-257.

Danielsson J, Hartmann P, Vries C de (1998): The cost of conservatism. Risk, 1(11):101-103.

Danielsson J, Macrae R (2011): The appropriate use of risk models. voxeu.org, 16 June 2011

Diebold FX, Mariano R (1995): Comparing Predictive Accuracy. Journal of Business and Economic Statistics, 13:253-265.

Diebold FX, Schuermann T, Stroughair J (2000): Pitfalls and Opportunities in the Use of Extreme Value Theory in Risk Management. Journal of Risk Finance, 1:30-36.

Dowd K (2005): Measuring market risk. New York, John Wiley \& Sons.

European Savings Banks Group (ESBG) (2010): ESBG Position in the CEBS consultation on "CEBS Guidelines on aspects of the management of concentration risk under the supervisory review process" (CP31). ESBG position paper, no. 0338/2010. 
Embrechts P, Resnick IS, Samorodnitsky G (1999): Extreme value theory as a risk management tool. North American Actuarial Journal, 3(2):30-41.

Gencay R, Selcuk F, Ulugulyagc1 A (2003): High volatility, thick tails and extreme value theory in Value-at-Risk estimations. Insurance: Mathematics and Economics, 33(2):337-356.

Gencay R, Selcuk F (2004): Extreme value theory and Value-at-Risk: Relative performance in emerging markets. International Journal of Forecasting, 20(2):287-303.

Greenspan A (2005): Reflections on central banking. In: The Greenspan Era: Lessons for the Future. Federal Reserve Bank of Kansas City, Jackson Hole, Wyoming, 25-27 August. Available at: http://www.federalreserve.gov/boarddocs/speeches/2005/20050826/.

Hansen PR (2005): A Test for Superior Predictive Ability. Journal of Business and Economic Statistics, 23(4):365-380.

Harvey D, Leybourne SJ, Newbold P (1998): Tests for Forecast Encompassing. Journal of Business and Economic Statistics, 16(2):254-259.

Harvey D, Newbold P (2000): Tests for Multiple Forecast Encompassing. Journal of Applied Econometrics, 15(5):471-482.

Holton AG (1998): Simulating Value-at-Risk. Risk, 11(5):60-63.

Hull J, White A (1998): Incorporating volatility updating into the Historical Simulation method for Value at Risk. Journal of Risk, (1):1-19.

Inui K, Kijima M (2005): On the Significance of Expected Shortfall as a Coherent Risk Measure. Journal of Banking and Finance, 29(4):853-864.

Knight MD (2008): Now you see it, now you don't: risk in the small and in the large. Speech delivered at the Eighth Annual Risk Management Convention of the Global Association of Risk Professionals, 27-28 February. Available at: http://www.bis.org/speeches/sp080229.htm.

Kondor I, Varga-Haszonits I (2008): Feasibility of Portfolio Optimization under Coherent Risk Measures. http://arxiv.org/pdf/0803.2283.pdf

Kourouma L et al. (2012): Extreme Value at Risk and Expected Shortfall during Financial Crisis. CERAG (Centre d'études et de recherches appliquées à la gestion), halshs-00658495.

Kupiec P (1995): Techniques for verifying the accuracy of risk management models. Journal of Derivatives, 3(2):73-84.

Linton LR, Harder LD (2007): Biology 315-Quantitative Biology Lecture Notes. University of Calgary, Calgary, AB.

Lopez AJ (1998): Methods for evaluating value-at-risk estimates. Federal Reserve Bank of New York, Economic Policy Review, 4(3):3-17.

Maghyereh IA, Al-Zoubi AH (2006): Value-at-risk under extreme values: the relative performance in MENA emerging stock markets. International Journal of Managerial Finance, 2(2):154-172.

McCracken MW (2000): Robust Out-of-Sample Inference. Journal of Econometrics, 99(2):195-223.

McNeil A (1997): Estimating the tails of loss severity distributions using extreme value theory. ASTIN Bulletin, 27:117-137.

McNeil AJ, Frey R (2000): Estimation of Tail-related Risk Measures for Heteroscedastic Financial Time Series: An extreme value approach. Journal of Empirical Finance, 7(3-4):271-300.

Mendes B (2000): Computing robust risk measures in emerging equity markets using extreme value theory. Emerging Markets Quarterly, 4(2):25-41.

Nyströmand K, Skoglund J (2002): Univariate Extreme Value Theory, GARCH and Measures of Risk. Swedbank, Working Paper, Group Financial Risk Control, Sweden.

Pattarathammas S, Mokkhavesa S, Nilla-Or P (2008): Value-at-Risk and Expected Shortfall under Extreme Value Theory Framework: An Empirical Study on Asian Markets [Online] // Thammasat Business School.—June 2008-une 20, 2013.—http://www.bus.tu.ac.th. 
Silva A, Mendes B (2003): Value-at-risk and extreme returns in Asian stock markets. International Journal of Business, 8(1):17-40.

Silverman BW (1986): Density Estimation for Statistics and Data Analysis. London, Chapman and Hall.

Sullivan R, Timmermann A, White H (2003): Forecast Evaluation with Shared Data Sets. International Journal of Forecasting, 19(2):217-227.

Yamai Y, Yoshiba T (2002): On the Validity of Value-at-Risk: Comparative Analyses with ExpectedShortfall. Monetary and Economic Studies, 20(1):57-86.

Yamai Y, Yoshiba T (2005): Value-at-risk versus expected shortfall: A practical perspective. Journal of Banking \& Finance, 29(4):997-1015.

West KD (1996): Asymptotic Inference about Predictive Ability. Econometrica, 64(5):1067-1084.

West KD, McCracken MW (1998): Regression Based Tests of Predictive Ability. International Economic Review, 39:817-840.

West KD (2001): Tests for Forecast Encompassing when Forecasts Depend on Estimated Regression Parameters. Journal of Business and Economic Statistics, 19(1):29-33.

White H (2000): A Reality Check for Data Snooping. Econometrica, 68(5):1097-1126.

Zar JH (1984): Biostatistical analysis. 2nd edition. Englewood Cliffs, Prentice-Hall.

Žiković S, Aktan B (2011): Decay Factor Optimisation in Time Weighted Simulation-Evaluating VaR Performance. International Journal of Forecasting, 27(4):1147-1159. 